\title{
Effect of particle surface area on ice active site densities retrieved from droplet freezing spectra
}

\author{
Hassan Beydoun, Michael Polen, and Ryan C. Sullivan \\ Center for Atmospheric Particle Studies, Carnegie Mellon University, Pittsburgh, PA, USA \\ Correspondence to: Ryan C. Sullivan (rsullivan@cmu.edu) \\ Received: 15 December 2015 - Published in Atmos. Chem. Phys. Discuss.: 18 January 2016 \\ Revised: 16 September 2016 - Accepted: 28 September 2016 - Published: 28 October 2016
}

\begin{abstract}
Heterogeneous ice nucleation remains one of the outstanding problems in cloud physics and atmospheric science. Experimental challenges in properly simulating particle-induced freezing processes under atmospherically relevant conditions have largely contributed to the absence of a well-established parameterization of immersion freezing properties. Here, we formulate an ice active, surface-sitebased stochastic model of heterogeneous freezing with the unique feature of invoking a continuum assumption on the ice nucleating activity (contact angle) of an aerosol particle's surface that requires no assumptions about the size or number of active sites. The result is a particle-specific property $g$ that defines a distribution of local ice nucleation rates. Upon integration, this yields a full freezing probability function for an ice nucleating particle.

Current cold plate droplet freezing measurements provide a valuable and inexpensive resource for studying the freezing properties of many atmospheric aerosol systems. We apply our $g$ framework to explain the observed dependence of the freezing temperature of droplets in a cold plate on the concentration of the particle species investigated. Normalizing to the total particle mass or surface area present to derive the commonly used ice nuclei active surface (INAS) density $\left(n_{\mathrm{s}}\right)$ often cannot account for the effects of particle concentration, yet concentration is typically varied to span a wider measurable freezing temperature range. A method based on determining what is denoted an ice nucleating species' specific critical surface area is presented and explains the concentration dependence as a result of increasing the variability in ice nucleating active sites between droplets. By applying this method to experimental droplet freezing data from four different systems, we demonstrate its ability to interpret im-
\end{abstract}

mersion freezing temperature spectra of droplets containing variable particle concentrations.

It is shown that general active site density functions, such as the popular $n_{\mathrm{s}}$ parameterization, cannot be reliably extrapolated below this critical surface area threshold to describe freezing curves for lower particle surface area concentrations. Freezing curves obtained below this threshold translate to higher $n_{\mathrm{S}}$ values, while the $n_{\mathrm{S}}$ values are essentially the same from curves obtained above the critical area threshold; $n_{\mathrm{s}}$ should remain the same for a system as concentration is varied. However, we can successfully predict the lower concentration freezing curves, which are more atmospherically relevant, through a process of random sampling from $g$ distributions obtained from high particle concentration data. Our analysis is applied to cold plate freezing measurements of droplets containing variable concentrations of particles from NX illite minerals, MCC cellulose, and commercial Snomax bacterial particles. Parameterizations that can predict the temporal evolution of the frozen fraction of cloud droplets in larger atmospheric models are also derived from this new framework.

\section{Introduction}

Above water's homogenous freezing temperature near $-38^{\circ} \mathrm{C}$, supercooled cloud droplets can only crystallize on a rare subset of atmospheric aerosol particles termed ice nucleating particles (INPs) (Baker and Peter, 2008; Vali et al., 2015). The scarcity of these particles directly affects cloud structure, evolution, and precipitation via inducing the Wegener-Bergeron-Findeisen (WBF) process, where ice crystals rapidly grow at the expense of liquid cloud droplets 
in mixed-phase clouds. Ice nucleation thus plays a crucial role in determining cloud evolution, lifetime, and properties, creating important feedbacks between aerosols, clouds, precipitation, and climate (Pruppacher and Klett, 1997; Rosenfeld et al., 2008). As a result, most precipitation over land is induced by cloud glaciation (Cantrell and Heymsfield, 2005; Mülmenstädt et al., 2015). Accurate representation of cirrus and mixed-phase clouds in atmospheric models therefore necessitates properly parameterizing the heterogeneous ice nucleation process (DeMott et al., 2010; Eidhammer et al., 2009; Hoose et al., 2010; Liu and Penner, 2005) for different aerosol source types and compositions that possess a wide range of heterogeneous ice nucleation activities (Phillips et al., 2008, 2013).

Great challenges in observing the actual heterogeneous ice nucleation nanoscale process is the main culprit impeding the formulation of a consistent and comprehensive framework that can accurately and efficiently represent heterogeneous ice nucleation in atmospheric models (Cantrell and Heymsfield, 2005); we still do not understand what precisely controls the ice nucleation ability of ice active surface sites that catalyze ice embryo formation. There are currently two competing views on the dominant factors that control the heterogeneous ice nucleation process: the stochastic vs. deterministic framework (Niedermeier et al., 2011; Vali, 2014). The stochastic framework assumes that freezing occurs with equal probability at any point across a particle's surface and can be constrained with a temperature-dependent ice nucleation rate (Pruppacher and Klett, 1997). This effectively yields time-dependent freezing and an element of non-repeatability (Vali, 2008). On the other hand, in the deterministic framework, ice nucleation is dictated by ice active surface sites (Fletcher, 1969; Levine, 1950; Meyers et al., 1992; Sear, 2013). Each active site has a characteristic critical freezing temperature, with the site with the highest critical temperature always initiating crystallization instantly (Vali, 2008). Careful examination of the experimental results published by Vali (2014) indicates that the very nature of the process need not be in contention. These results suggest that there is a strong spatial preference on where nucleation occurs, supporting a model of discrete active sites. However, variability in freezing temperatures still occurs, indicating that a stochastic element also exists. Considering several decades of experimental work and theoretical considerations (Ervens and Feingold, 2013; Murray et al., 2012; Vali, 1994, 2014; Vali and Stransbury, 1966; Wright et al., 2013; Wright and Petters, 2013), the role of time has been determined to play a much weaker role than temperature does. It remains to be seen whether the difference is significant enough for timedependent freezing to be completely omitted in atmospheric models.

The debate over how to properly parameterize heterogeneous ice nucleation has important implications on how freezing processes are represented in atmospheric models (Hoose et al., 2010; Hoose and Möhler, 2012; Koop et al., 2000; Phillips et al., 2008, 2013), and also reflects our fundamental understanding of this nucleation process. Ervens and Feingold (2012) tested different nucleation schemes in an adiabatic parcel model and found that critical cloud features, such as the initiation of the WBF process, liquid water content, and ice water content, all diverged for the different ice nucleation parameterizations. This strongly affected cloud evolution and lifetime. The divergence was even stronger when the aerosol size distribution was switched from monodisperse to polydisperse. Similar sensitivities of adiabatic parcel models to time-dependent freezing were shown in Wright and Petters (2013) and Vali and Snider (2015).

A new parameterization, starting from classical nucleation theory, is formulated in this paper. The new framework is stochastic by nature to properly reflect the randomness of ice embryo growth and dissolution, and assumes that an INP can exhibit variability in active sites along its surface (what will be referred to as internal variability) and variability in active sites between other particles of the same species (what will be referred to as external variability). A new method is presented to analyze and interpret experimental data from the ubiquitous droplet freezing cold plate method using this framework, and parameterize these experimental results for use in cloud parcel models. New insights into the proper design of cold plate experiments and the analysis of their immersion freezing datasets to accurately describe the behavior of atmospheric INPs are revealed. Based on experimental observations and the new framework, we argue that active site schemes that assume uniform active site density such as the popular $n_{\mathrm{s}}$ parameterization - a deterministic framework that assigns an active site density as a function of temperature (Hoose et al., 2008; Vali, 1971) - are unable to consistently describe freezing curves over a wide surface area range. This shortcoming is argued to be one of the causes of the discrepancies in retrieved $n_{\mathrm{s}}$ values of the same ice nucleating species using different measurement methods and particle in droplet concentrations (Emersic et al., 2015; Hiranuma et al., 2015a; Wex et al., 2015).

\section{Classical nucleation theory}

Ice nucleation is a fundamentally stochastic process brought about by the random formation, growth, and dissolution of critically sized ice germs that overcome the energy barrier associated with the phase transition (Pruppacher and Klett, 1997; Vali and Stransbury, 1966). A homogenous ice nucleation rate for a given volume of supercooled water can therefore be defined from a Boltzmann-type formulation:

$J(T)=C \exp \left(-\frac{\Delta G}{k T}\right)$,

where $J$ is the ice nucleation rate and has units of freezing events/(time $\times$ volume). $\Delta G$ is the energy barrier to crys- 
tallization from liquid water as defined in Pruppacher and Klett (1997) and Zobrist et al. (2007). $T$ is temperature, $k$ the Boltzmann constant, and $C$ is a constant. For typical cloud droplet volumes, a temperature of about $-38^{\circ} \mathrm{C}$ is typically required for the homogeneous ice nucleation rate to become significantly fast such that freezing occurs within minutes or less. At temperatures between -38 and $0{ }^{\circ} \mathrm{C}$, a catalyst is required to initiate freezing of cloud droplets. Certain rare aerosol particles - INPs - can act as these catalysts and induce heterogeneous ice nucleation in the atmosphere.

In expanding to heterogeneous ice nucleation, the simplest approach is to assume that instead of ice germ formation occurring randomly throughout a bulk volume of supercooled water, ice nucleation is initiated on a surface. The surface reduces the nucleation energy barrier $\Delta G$ by a factor $f$, dependent on the contact angle between liquid water and the material. The contact angle $\theta[0, \pi]$ is actually a proxy for the water-surface interaction system, with smaller values of $\theta$ indicating that the surface is a better nucleant. The surface's measured water contact angle cannot actually be simply used to predict its ice nucleation efficiency. The extreme limit of a contact angle of $0^{\circ}$ is therefore a perfect ice nucleant, diminishing the energy barrier fully and immediately inducing freezing at the thermodynamic freezing point of water at $0{ }^{\circ} \mathrm{C}$. The heterogeneous ice nucleation rate for a volume of water containing a total surface area of INPs therefore can be defined as in Pruppacher and Klett (1997):

$J(T)=C \exp \left(-\frac{f(\theta) \Delta G}{k T}\right)$,

where $J$ in this case would be expressed as freezing events $/$ (time $\times$ surface area).

The simplest stochastic formulation hypothesizes that the nucleation rate is uniform across the INP's surface, i.e., makes a single contact angle assumption. For a large statistical ensemble of droplet-INP pairings the number of frozen droplets after some time $t$ resembles a first order chemical decay (Pruppacher and Klett, 1997):

$N_{\mathrm{f}}(T, t)=N(1-\exp (-J(T) A t))$,

where $N_{\mathrm{f}}$ is the fraction of droplets frozen after time $t$ at temperature $T, N$ is the total number of particle-droplet pairings and $A$ is the surface area of each individual INP (assumed to be the same for all particles). Furthermore, a probability of ice nucleation, $P_{\mathrm{f}}$, at the single droplet-particle level can be defined as

$P_{\mathrm{f}}=1-\exp (-J A t)$

\section{The formulation of $g$ : a continuum approach of active site activity to describe heterogeneous ice nucleation}

Given the large variability in particle surface composition and structure across any one particle, which in turn deter- mines the activity (or contact angle, $\theta$ ) of a potential ice nucleating site, a different approach is to assume that the heterogeneous nucleation rate will vary along the particle-droplet interface. Since the critical nucleation area $\left(\sim \mathrm{nm}^{2}\right)$ is much smaller than the total particle area $\left(\sim \mu \mathrm{m}^{2}\right)$, we apply a continuum assumption for the ice active site activity $(\theta)$ available across a particle's surface without assumptions about the size or number of active sites per particle surface area. The new resulting probability of freezing is

$P_{\mathrm{f}}=1-\exp \left(-t \int J \mathrm{~d} A\right)$

where $J$ is now a freezing rate that is allowed to vary for each specific small segment of the particle's surface area, $\mathrm{d} A$. To define the freezing probability as a function of a contact angle distribution, the surface integral (Eq. 5) is transformed into a line integral via the newly defined $g$ parameter and normalized to the total available surface area:

$g(\theta)=\frac{1}{A} \frac{\mathrm{d} A}{\mathrm{~d} \theta}$

and the freezing probability for a droplet-particle pair becomes

$P_{\mathrm{f}}=1-\exp \left(-t A \int_{0}^{\pi} J(T, \theta) g(\theta) \mathrm{d} \theta\right)$,

where $g$ is a probability density function describing the continuous active site density of the INP's surface. To our knowledge, this is the first use of a continuum description of ice nucleating activity to describe the freezing behavior of an individual particle. One of the key unique features of our approach is that the number or size of the individual active sites does not have to be assumed or retrieved in order to predict the freezing probabilities. The implications of these unique features in our framework and the choice of a normal distribution for the contact angle will be explored and justified in a following section.

In this work, the internal variability of an individual INP expresses the heterogeneity of its ice nucleating surface. A wider (larger $\sigma$ ) $g$ distribution describes a greater particle internal variability of ice active surface site properties or contact angles present on that one particle. This is in contrast to the external variability of an ice nucleating species or type, which expresses how diverse a population of particles is in their ice nucleation activities. External variability accounts for differences in the $g$ distributions of individual particles between particles of the same type (such as particles composed of the same mineral phases).

We hypothesize that experimentally probed systems can be interpreted as exhibiting internal and external variability based on differences in freezing temperatures of different droplets containing the same material, i.e., the freezing temperature spectrum of a droplet array. The model will be 
shown to provide a conceptual explanation of what this variability, be it internal or external, stems from. We provide this as a potential explanation for discrepancies in the measured values of the popular deterministic scheme $n_{\mathrm{s}}$ (Hoose and Möhler, 2012; Vali, 2014) for different particle concentrations and consequently different measurements methods. In the following sections, the model is developed further to shed light on the impact of the $g$ distribution on time-dependent freezing, the contrasting internally and externally variable nature of a species' ice nucleating activity, and the dependence of $g$ on particle size.

\subsection{Internal variability and its impact on time-dependent freezing}

To explore the importance of accounting for ice nucleating variability along a single particle's surface (internal variability) we examined the temperature-dependent freezing curves of droplets with single large-ash particles immersed in them from Fornea et al. (2009). Their experiments were performed with cooling rates of $1^{\circ} \mathrm{Cmin}^{-1}$. Figure 1 displays their experimental data (red dots), a single contact angle $(\theta)$ fit to their data (red solid line) that assumes no internal variability, and a $g$ distribution fit using multiple $\theta$ values (solid blue line) that allow for internal variability. Fornea et al. (2009) retrieved their experimental data points by averaging the observed freezing temperature of the same ash particle-droplet pair after multiple freezing cycles. The averaged values are denoted freezing probabilities since they represent the chance of freezing occurring at that temperature. The ash particle diameter was around $300 \mu \mathrm{m}$, clearly much larger than atmospheric particle sizes. Five different particle samples of Mount St. Helens ash were probed in the study; the one that exhibited the broadest range of freezing temperature was chosen for the examination conducted in this section.

To fit a $g$ distribution to an empirical freezing curve, a least square error approach is implemented. A matrix of freezing probabilities is generated for all possible $g$ distributions. If the experimental freezing curve has been retrieved from experiments in which the temperature is dictated by a nonconstant cooling rate, an expression that satisfies this condition must be used:

$P_{\mathrm{f}}=1-\exp \left(-A \int_{0}^{t} \int_{0}^{\pi} J(T(t), \theta) g(\theta) \mathrm{d} \theta \mathrm{d} t\right)$.

In Eq. (8) $J$ is a function of time because temperature varies with time. If the cooling rate $\dot{T}$ is constant, a simple change of variable can be applied:

$P_{\mathrm{f}}=1-\exp \left(-\frac{A}{\dot{T}} \int_{T_{i}}^{T_{f}} \int_{0}^{\pi} J(T, \theta) g(\theta) \mathrm{d} \theta \mathrm{d} T\right)$.

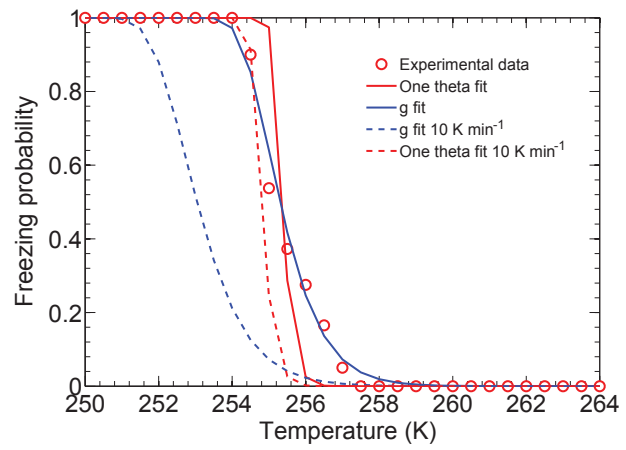

Figure 1. Experimentally determined freezing probabilities and fits from freezing of a droplet containing a single large $\sim 300 \mu \mathrm{m}$ diameter volcanic ash particle, from Fornea et al. (2009). Red dots are experimental freezing probabilities retrieved from repeated droplet freezing measurements. The red line is a fit to the data using classical nucleation theory and the assumption of a single contact angle $(\theta)$. The blue line is a fit to the data using the $g$ framework developed here, which describes a Gaussian distribution of $\theta$. The $g$ fit has a least square error sum of $0.0197, \mu=1.65$ and $\sigma=0.135$. The dotted red line is the simulated freezing curve resulting from a single $\theta$ distribution for a simulated cooling rate of $10 \mathrm{~K} \mathrm{~min}^{-1}$. The dotted blue line is the freezing curve from a multiple $\theta$ distribution described by $g$ after the same simulated cooling rate.

Equation (9) is therefore used to fit the constant cooling rate dataset from Fornea et al. (2009) considered here as well as datasets considered later in the paper. $J(T, \theta)$ is evaluated using classical nucleation theory parameters presented in Zobrist et al. (2007).

The $g$ fit performs much better in capturing the behavior of the observed freezing temperature spectrum in Fig. 1, as expected given the greater degrees of freedom allowed for the multiple $\theta$ fit. The single $\theta$ fit has a steeper dependence on temperature; the double exponential temperature dependence of the freezing probability in Eq. (4) ( $J$ is an exponential function of temperature in itself, as can be seen in Eq. 2) results in an approximate temperature step function. The diversity of nucleating ability on the particle surface captured by the $g$ parameter offsets some of the steepness and yields a more gradual freezing curve, more similar to the actual experimental freezing probability curve.

Two droplet freezing probability fits (dotted lines) are also plotted in Fig. 1 using the single and multiple $\theta$ fits but with a larger cooling rate of $10 \mathrm{~K} \mathrm{~min}^{-1}$. One fit uses the same $g$ distribution used previously, while the additional single $\theta$ fit is approximated as a normal distribution with a near-zero standard deviation, similar to a Dirac delta function. The resultant freezing probabilities are then computed and plotted for every $T$ using Eq. (9). It can be seen that the $g$ fit retains much stronger cooling rate dependence, with the $g$ freezing probability curve shifting about $2 \mathrm{~K}$ colder and the single $\theta$ curve shifting just $0.5 \mathrm{~K}$ colder for the faster $10 \mathrm{~K} \mathrm{~min}^{-1}$ cooling rate. The $2 \mathrm{~K}$ prediction presented here is still smaller than 
the one retrieved experimentally by Fornea et al. (2009) for varying the cooling rate from 1 to $10 \mathrm{~K} \mathrm{~min}^{-1}$, which was measured to be $3.6 \mathrm{~K}$. However, it is unclear which of the samples presented in their work corresponds to this change in median freezing temperature, as it is only mentioned as an average decrease in temperature for all of the different samples tested.

This numerical exercise shows that wider $g$ distributions theoretically yield stronger time dependence due to the partial offset of the strong temperature dependence that the nucleation rate in Eq. (2) exhibits. The result emphasizes that how the active sites are modeled has consequences on what physical parameters (e.g., time, temperature, cooling rate) can influence the freezing outcome and predicted droplet freezing temperature spectrum (Broadley et al., 2012) and that model parameters need to be tested under different environmental conditions (e.g., different cooling rates) to properly test their validity. In Fig. 1, a wider $g$ distribution resulted in a higher sensitivity to cooling rate, which resulted in a shift of the freezing curve to lower temperatures as the system was cooled at a faster rate. This significant change in the freezing probability's sensitivity to temperature is the cause of the more gradual rise in the freezing probability for the system when applying a non-Dirac delta $g$ distribution. This is effectively enhancing the stochastic element in the particle's ice nucleation properties. The enhancement of the stochastic element brings about a more important role for time as shown in Fig. 1. The finding of this exercise is consistent with previously published work on time-dependent freezing such as those reported by Barahona (2012), Wright and Petters (2013), and Herbert et al. (2014), amongst others.

\subsection{Defining $g$ as a normal distribution of ice nucleation activity}

The fit for a particle freezing curve such as the one considered in the previous section (Fig. 1) does not have a unique solution. There are, mathematically speaking, infinite solutions for the $g$ distributions that produce a representative freezing curve. In any considered distribution, an ascending tail with increasing contact angle represents a competition between more active but less frequent surface sites, and less active but more frequent sites. Sites with lower activity and lower frequency have essentially zero chance of contributing to the overall freezing probability, primarily due to the nucleation rate's, $J$, exponential dependence on the energy barrier to nucleation and the freezing probability's exponential dependence on $J$ as shown in Eqs. (2) and (7). It is therefore sufficient to conceptualize that the particle has a well-defined monotonic spectrum of active sites increasing in frequency while decreasing in strength. The spectrum is modeled as a continuum of ice nucleation activity described by the $g$ distribution, as depicted on the upper right hand corner in Fig. 2. Figure 2 also shows part of the $g$ distribution (the ascending part representing the monotonic spectrum of active sites)

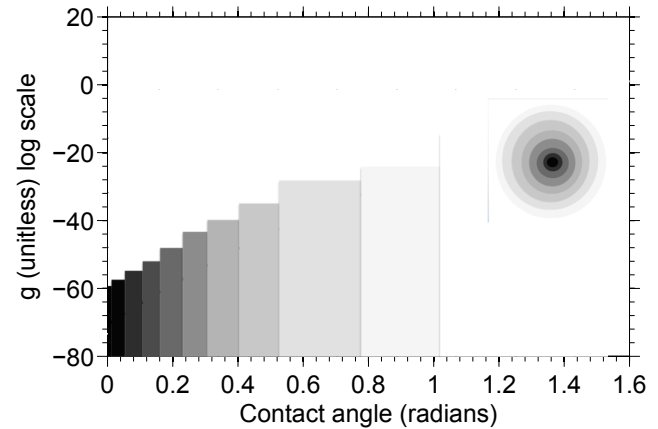

Figure 2. Upper right inset displays the distribution of ice nucleation activity (contact angle, $\theta$ ) for a representative spectrum of a particle's ice nucleating activity. The less active (white) surface sites have more surface coverage while the more active (black) surface sites have less coverage. The probability distribution function for the $g$ distribution $(\mu=1.65$ and $\sigma=0.135$, retrieved in Sect. 3.1) ascent in log space is plotted with numerical bins. The darker colors are used to highlight the stronger ice nucleating activity at smaller contact angles $(\theta)$.

retrieved for the case example in Sect. 3.1 (log scale) discretized into numerical bins, where the height of each bin represents the abundance of that $\theta$ across the particle's surface. The area in each column thus represents the total surface area with that value of $\theta$. As in Fig. 2's inset, the darker colors are used to emphasize more active ice nucleating activity at the smaller contact angles.

The ascending part of the curve of the normal $g$ distribution covering the smallest (most active) values of $\theta$ in Fig. 2 can therefore capture this active site model. The wider the defined $g$ distribution (i.e., for a larger standard deviation, $\sigma)$ the more diverse the considered system is in its internal variability of ice nucleation activity. Since the freezing probability is determined solely by a fraction of the ascent of the normal distribution - as this captures the rare but most active sites that determine the actual freezing rate $J$ and freezing probability $P_{\mathrm{f}}-$ the following approximation to Eq. (9) can be made:

$$
\begin{aligned}
P_{\mathrm{f}} & =1-\exp \left(-\frac{A}{\dot{T}} \int_{T_{i}}^{T_{f}} \int_{0}^{\pi} J(T, \theta) g(\theta) \mathrm{d} \theta \mathrm{d} T\right) \\
& \approx 1-\exp \left(-\frac{A}{\dot{T}} \int_{T_{i}}^{T_{f}} \int_{\theta_{\mathrm{c}_{1}}}^{\theta_{\mathrm{c}_{2}}} J(T, \theta) g(\theta) \mathrm{d} \theta \mathrm{d} T\right),
\end{aligned}
$$

where $\theta_{\mathrm{c}_{1}}$ and $\theta_{\mathrm{c}_{2}}$ are the approximate cutoff points in the $g$ distribution that contain the critical range of the most active contact angles. Outside $\left[\theta_{\mathrm{c}_{1}}, \theta_{\mathrm{c}_{2}}\right]$ the less active contact angles have a negligible contribution to the actual manifested freezing rate and freezing probability. The critical contact angle range is a strong function of the area of the particle. 

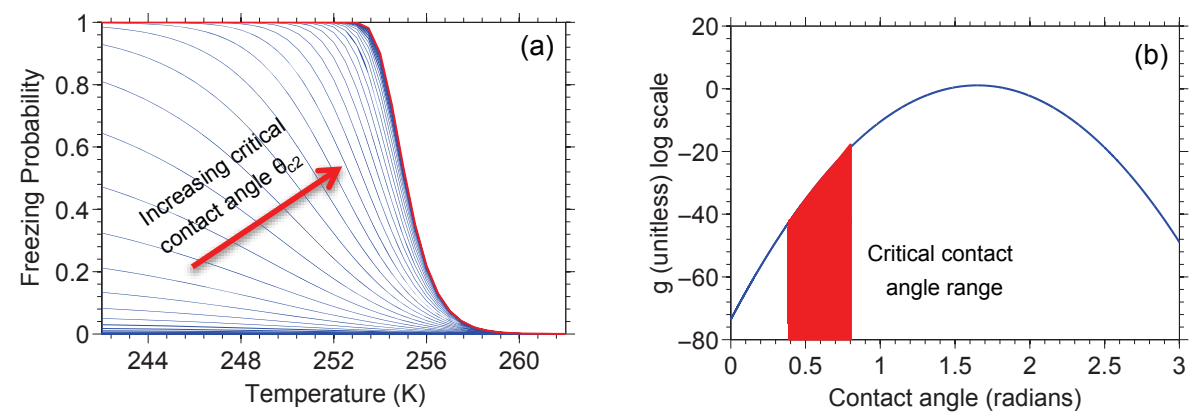

Figure 3. (a) Identifying the critical contact angle range. The thin blue curves are retrieved from application of the simplified Eq. (10), which approximates the freezing probability by integrating over a smaller contact angle range, $\left[\theta_{\mathbf{c}_{1}}, \theta_{\mathbf{c}_{2}}\right]$, while the thick red curve is obtained from application of the complete Eq. (7), which integrates over the full contact angle range. Both approaches use the same $g$ distribution retrieved for the case example in Sect. 3.1 with $\mu=1.65$ and $\sigma=0.135$. (b) The $g$ distribution from the case example in Sect. 3.1 is plotted in log scale and shows the critical contact angle range retrieved in Sect. $3.2\left(\theta_{\mathrm{c}_{1}} \approx 0.4 \mathrm{rad}\right.$ and $\left.\theta_{\mathrm{c}_{2}} \approx 0.79\right)$ in red.

The critical contact angles are determined numerically by identifying the range $\left[\theta_{\mathrm{c}_{1}}, \theta_{\mathrm{c}_{2}}\right]$ for which the freezing probability can be approximated using Eq. (10). Figure 3a illustrates the process of identifying $\theta_{\mathrm{c}_{2}}$. The blue curves represent freezing probabilities computed via integrating Eq. (10) from 0 to a variable $\theta_{\mathrm{c}_{2}}$. The red curve is the freezing probability computed from integrating across the full $\theta$ range. As $\theta_{\mathrm{c}_{2}}$ is increased, the resultant curve (blue) approaches the curve computed from the full $\theta$ range (red). For the example studied in Fig. 3 (same system examined in Sect. 3.1), a value of $\theta_{\mathrm{c}_{2}}=0.79 \mathrm{rad}$ results in a least square error below 0.01 for the freezing probability retrieved from Eq. (10) assessed against the freezing probability retrieved from Eq. (9). An identical approach is followed to determine $\theta_{\mathrm{c}_{1}}$.

Furthermore, the critical contact angle range can be used to estimate a hypothetical nucleating area of the particle - the total active site surface area where nucleation will take place. The nucleation area $A_{\text {nucleation }}$ can be estimated as follows:

$$
A_{\text {nucleation }}=A \int_{\theta_{\mathrm{c}_{1}}}^{\theta_{\mathrm{c}_{2}}} g(\theta) \mathrm{d} \theta \text {. }
$$

For the large-ash particle system analyzed in the previous section (Fig. 1) it is estimated that for an approximate diameter of $300 \mu \mathrm{m}$ and a cooling rate of $1 \mathrm{~K} \mathrm{~min}^{-1} \theta_{\mathrm{c}_{1}} \approx 0.4 \mathrm{rad}$ and $\theta_{\mathrm{c}_{2}} \approx 0.79 \mathrm{rad}$. Application of Eq. (11) yields a total ice active surface area estimate of $27 \mathrm{~nm}^{2}$. Classical nucleation theory estimates that the area of a single active site is $6 \mathrm{~nm}^{2}$ (Lüönd et al., 2010; Marcolli et al., 2007). The estimated total area of nucleation is therefore consistent with this value and supports the argument that competition between sites along the critical range of $\theta$ is taking place. However, the surface area where ice nucleation is occurring remains a very tiny fraction of the total particle surface. This further justifies the use of a continuum of surface area to define $g$ as $\mathrm{d} A / \mathrm{d} \theta$ (Eq. 6). The nucleating area is a function of both the $g$ Gaussian distribution of $\theta$ and the total surface area of the consid- ered particle. Figure $3 b$ shows the $g$ distribution in log scale and highlights in red the fraction of the distribution covered by the critical contact angle range. It is important to emphasize that the critical contact angles are variable parameters and not a property of the ice nucleating species. Therefore, for the same $g$ distribution the critical contact angles shift in the direction of decreasing activity (larger $\theta$ ) for smaller surface areas and increasing activity (smaller $\theta$ ) for larger surface areas.

\subsection{Using critical area analysis to predict droplet freezing spectra obtained in cold plate experiments}

Many droplet freezing array experimental methods such as those described in Broadley et al. (2012), Murray et al. (2011), Vali (2014), Wright and Petters (2013), and Hiranuma et al. (2015a) use atmospherically relevant particle sizes (hundreds of nanometers to a few microns in diameter) but create the droplet array from a prepared suspension of the particles of interest in water. The resultant particle concentrations are typically high and the number of particles present in each droplet has to be approximated using statistical methods. When total particle surface area is high enough we hypothesize that it is conceivable that a threshold is reached whereby most of the species' maximum possible external variability is already available within the particledroplet system. At this point, it is approximated that no additional diversity in external variability (ice active site ability or $\theta$ ) is created by further increasing the total particle surface area in the water volume; the external variability has effectively saturated. For the application of this model to cold plate data where droplets are prepared from a suspension of the species being investigated, the particle population in each droplet is treated as one aggregate surface (and thus one large particle) and a mean surface area value is assumed for the particle material in all the droplets in the array. This estimate is retrieved from the weight percentage of the material in the 

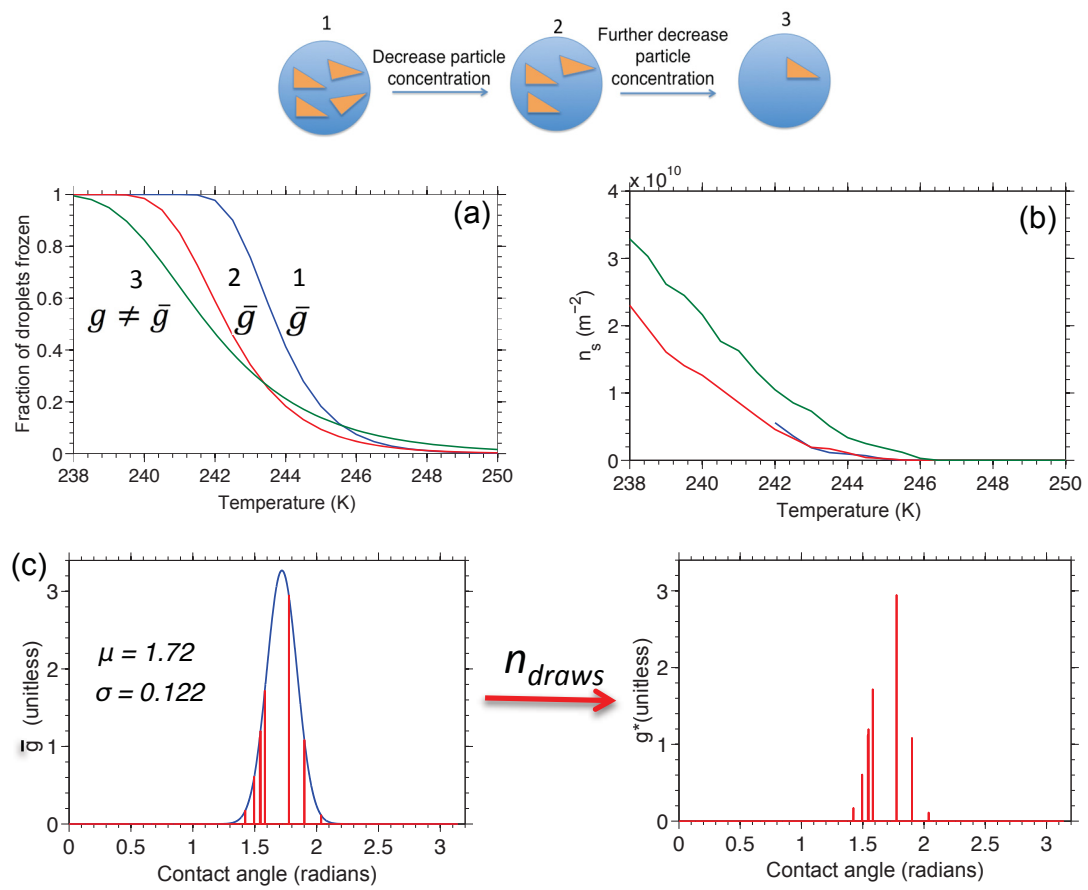

Figure 4. (Top) Schematic summarizing the procedure for determining the critical area. (a) The frozen fraction freezing curves shift to lower temperatures initially due solely to the decrease in total surface area of the INPs (curves 1 and 2). As the total surface area of the particles is decreased below the critical area threshold $(g \neq \bar{g})$ the slope of the freezing curve also broadens because the effective distribution of ice nucleating sites has changed - more external variability has been introduced (curve 3). (b) Ice active site density $\left(n_{\mathrm{S}}\right)$ retrieved from the frozen fraction plots on the left for the same three particle concentration systems. Above the critical area limit $(g=\bar{g})$ the two $n_{\mathrm{S}}$ curves are essentially the same, but below the critical area threshold $(g \neq \bar{g}) n_{\mathrm{S}}$ increases, even though the same particle species was measured in all three experiments. These exemplary frozen fraction and $n_{\mathrm{S}}$ curves were produced by fitting a $\bar{g}$ distribution to droplet freezing measurements of illite mineral particles from Broadley et al. (2012). (c) Schematic summarizing how $g^{*}$ is retrieved from $\bar{g}$ using $n_{\text {draws. }}$. In each draw a random contact angle from the full range of contact angles $[0, \pi]$ is chosen after which the value of $g^{*}$ at that contact angle (right) is assigned the value of $\bar{g}$ at the same contact angle (left).

water suspension and our best guess for a reliable surface area density which is how much surface area the particle material possesses relative to its mass (Hiranuma et al., 2015a, b).

Past the hypothesized surface area threshold, which will be referred to as the critical area, each member of the system's population (droplets with particles immersed in them) become approximately identical in their ice nucleation properties, and the theoretical frozen fraction can be expressed as

$$
F=P_{\mathrm{f}}(\text { one system })=1-\prod_{i=1}^{n} P_{\mathrm{uf}, i},
$$

where $F$ is the droplet frozen fraction, $n$ is the number of droplets, and $P_{\mathrm{uf}, i}$ is the probability that the droplet $i$ does not freeze. Further expanding the expression yields

$$
\begin{aligned}
F & =1-\exp \left[-t\left(\sum_{i=1}^{n} A_{i} \int_{0}^{\pi} J(\theta, T) g_{i}(\theta) \mathrm{d} \theta\right)\right] \\
& =1-\exp \left[-t \int_{0}^{\pi} J(\theta, T) \sum_{i=1}^{n}\left(A_{i} g_{i}\right) \mathrm{d} \theta\right] .
\end{aligned}
$$

Next the parameter $\bar{g}$ is defined:

$$
\bar{g}=\frac{\sum_{i=1}^{n}\left(A_{i} g_{i}\right)}{A_{\mathrm{t}}},
$$

where $A_{i}$ is the sum of all particle surface area available inside a given droplet $i$, and $A_{\mathrm{t}}$ is the mean particle surface area per droplet. Equation (13) then becomes

$\Rightarrow F=1-\exp \left(-t A_{\mathrm{t}} \int_{0}^{\pi} J(\theta, T) \overline{g(\theta)} \mathrm{d} \theta\right)$.

$\bar{g}$ is the arithmetic average of all the $g$ distributions for ensemble of particles in the droplet (each particle has its own 
$g$ distribution) with a cumulative area larger than the critical area of the species they belong to. Alternatively $\bar{g}$ can be thought of as the probability density function for all possible ice nucleating activity of a given species or particle type. It is worth mentioning that $\bar{g}$ is a true continuous probability density function. While the $g$ distribution of an individual particle is an approximate continuous function - due to the very small size of ice nucleating active sites $-\bar{g}$ contains all possible values of contact angles that an ice nucleating species can exhibit.

Above a certain surface area threshold it is conceptualized that the chance of an INP surface not possessing the entire range of ice nucleating activity $(\theta)$ becomes very small. The model therefore assumes that any particle or population of particles having a total surface area larger than the critical area can be approximated as having $\bar{g}$ describe the actual $g$ distribution of the individual particles. In other words, for large particles with more surface area than the critical area threshold, it is assumed that the external variability between individual particles will be very small, such that the particle population can just be described by one average continuous distribution of the ice nucleation activity, $\bar{g}$.

To resolve the $g$ distributions of the systems possessing particle surface areas smaller than the critical area the first step is to approximate the critical area. Experiments must start at very high particle mass concentrations to ensure the total surface area per droplet exceeds the critical area. For the illite mineral particle case study considered next, for example, high particle concentrations were those that resulted in total particle surface areas greater than about $2 \times 10^{-6} \mathrm{~cm}^{2}$. The particle number or surface area concentration is then decreased until the retrieved $g$ distribution (from the measured droplet freezing temperature spectrum for an array of droplets containing particles) can no longer be reasonably predicted by $\bar{g}$. This point can identify the parameter $A_{\mathrm{c}}$, the critical area of the species under study. A schematic of the procedure is summarized in Fig. 4.

Figure 5 shows experimental freezing curves (open symbols) for illite NX mineral particles taken from Broadley et al. (2012), with different particle surface area concentrations. Droplets of $10-20 \mu \mathrm{m}$ were used and cooled at a cooling rate of $5 \mathrm{~K} \mathrm{~min}^{-1}$. The curves from the highest particle concentration experiments, $7.42 \times 10^{-6}(6 \mathrm{~b})$ and $2.02 \times 10^{-6} \mathrm{~cm}^{2}(6 \mathrm{a})$, are used to approximate the critical area of the system by first fitting the $6 \mathrm{~b}$ curve with a $g$ distribution and then successfully predicting the 6a curve with the same $g$ distribution obtained from $6 \mathrm{~b}$ and applying a particle surface area correction. The fit to the $6 \mathrm{~b}$ curve is done using Eq. (9) and follows the same procedure of least square error fitting described in Sect. 3.1. This $g$ distribution is therefore assumed to be the $\bar{g}$ of the considered system with $\mu=1.72$ and $\sigma=0.122$. Note that above the threshold concentration $A_{\mathrm{c}}$, approximated here as occurring between $7.42 \times 10^{-6}$ and $2.02 \times 10^{-6} \mathrm{~cm}^{2}$, a change in the total available surface area $A$ is all that is required to account for how the change in

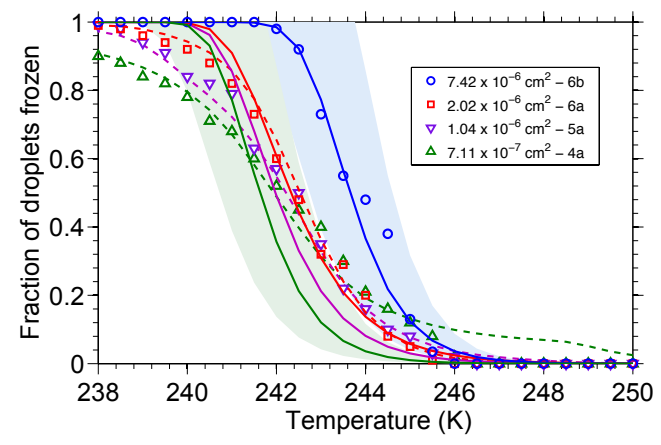

Figure 5. Experimental freezing curves for different surface area concentrations of illite mineral powder immersed in $10-20 \mu \mathrm{m}$ diameter water droplets taken from Broadley et al. (2012) (circles). Lines are modeled predictions of the same data using the $g^{*}$ distribution method. Solid lines are produced directly from the global $\bar{g}$ distribution first obtained from the high concentration system. The dashed lines are obtained by randomly subsampling the global $\bar{g}$ distribution to obtain $g^{*}$ and following a surface area correction, as described in the text. The shaded region shows the predicted temperature range over which freezing of droplets occurs for the surface area variability associated with the droplet diameter range of $10-20 \mu \mathrm{m}$ using $\bar{g}$ (i.e., running Eq. 9 with different values for $A$ ) for the highest and lowest particle concentration experiments.

particle concentration shifts the droplet freezing temperature curve. This is not the case when total area is less than the critical area $A_{\mathrm{c}}$, as discussed next.

Moving to the lower concentration freezing curves, $1.04 \times 10^{-6} \mathrm{~cm}^{2}(5 \mathrm{a})$ and $7.11 \times 10^{-7} \mathrm{~cm}^{2}$ (4a) the transition to below the critical area begins to be observed. The solid lines attempt to predict the experimental data points using $\bar{g}$. Predicting experimental data points for the $1.04 \times 10^{-6} \mathrm{~cm}^{2}$ (5a) system with the same $\bar{g}$ distribution captures the $50 \%$ frozen fraction point but fails to account for the broadness on the two ends of the temperature spectrum. The prediction from $\bar{g}$ completely deteriorates in quality for the lowest concentration experiments, $7.11 \times 10^{-7} \mathrm{~cm}^{2}(4 \mathrm{a})$, as it neither captures the temperature range over which freezing is occurring nor the $50 \%$ frozen fraction point.

We investigated a similar trend when freezing droplets containing commercial Snomax (York International), and MCC cellulose (Sigma-Aldrich) particles immersed in oil in our in-house cold plate system, described by Polen et al. (2016). The relevant system details are that particlecontaining water droplets of approximately $500-700 \mu \mathrm{m}$ in diameter are immersed in squalene oil, analogous to the method of Wright et al. (2013), and the droplets' freezing temperature is determined optically during a constant $1 \mathrm{~K} \mathrm{~min}^{-1}$ cooling cycle. A new sample solution was prepared of the material being tested before every experiment to avoid potential changes to the ice nucleation ability due to ageing. Ultrapure Milli-Q water was used to minimize 

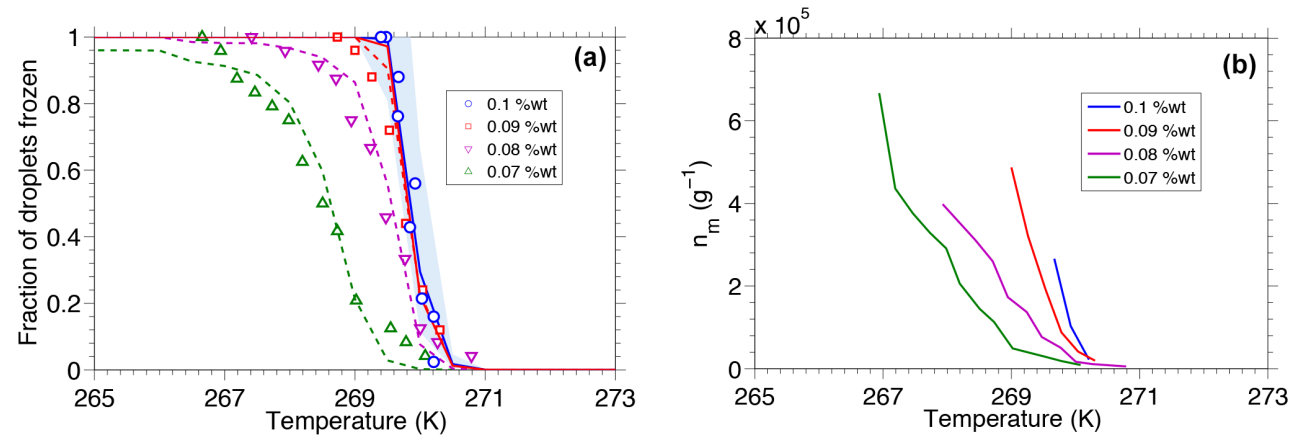

Figure 6. (a) Experimental freezing curves for different mass concentrations of commercial Snomax powder immersed in 500-700 $\mu \mathrm{m}$ diameter water droplets obtained using the CMU cold plate (circles). Solid lines are fits produced from randomly sampling from the $\bar{g}$ distribution retrieved from the highest concentration freezing curve $(0.1 \% \mathrm{wt})$. Dashed lines are fits produced from randomly sampling from the $\bar{g}$ distribution and a surface area correction. The second highest concentration freezing curve $(0.09 \%$ wt) is used to confirm the critical area threshold had been exceeded. The shaded region represents the effect of variability in surface area as in Fig. 5 but for a droplet diameter range of 500-700 $\mu \mathrm{m}$ for the highest particle concentration. (b) Ice active site density $\left(n_{\mathrm{m}}\right)$ retrieved from the frozen fraction data on the left. A trend of decreasing $n_{\mathrm{m}}$ with decreasing concentration is observed for the droplets containing Snomax.

any background impurities that could provide a source of ice nucleants or solutes that would alter the freezing temperature of the water. Around $500.1 \mu \mathrm{L}$ droplets were then produced with a pipette from this solution. Each freezing experiment was repeated at least twice, with about 50 droplets per run, to confirm that the independently retrieved frozen fractions fall within $1 \mathrm{~K}$ of each other for each replicate experiment. Figure 6a shows decreasing concentration freezing curves for droplets containing Snomax particles. Snomax is a freeze-dried powder manufactured from nonviable Pseudomonas syringae bacteria and is commonly used to make artificial snow due to its very mild freezing temperature of -3 to $-7^{\circ} \mathrm{C}$. Its ice nucleation properties are attributed to large protein aggregates, and Snomax is often used as a proxy for atmospheric biological INP (Pandey et al., 2016; Polen et al., 2016; Wex et al., 2015). A similar approach was undertaken in which $\bar{g}$ was retrieved using the highest concentration freezing curve (solid blue line). The surface area density is assumed to be $1 \mathrm{~m}^{2} \mathrm{~g}^{-1}$ though it is recognized that given the protein-aggregate-based ice nucleating mechanism of Snomax it is difficult to attribute a surface area of nucleation to a mass of Snomax powder. However, a surface area value needs to be assumed to retrieve the ice nucleating properties using the framework presented here for the sake of comparing Snomax to the other systems. For an assumed critical area of $4 \times 10^{-6} \mathrm{~cm}^{2}$ (the surface area at $\left.0.1 \mathrm{wt} \%\right) \bar{g}$ was found to have $\mu=0.66$ and $\sigma=0.055$. Unlike the illite dataset considered first, only $50 \%$ of the freezing behavior of the second highest concentration freezing curve is captured by a frozen fraction retrieved from $\bar{g}$ (solid red line). Further lowering the concentration produces a similar trend previously observed for the droplets containing illite, with similar freezing onsets at higher temperatures but significant divergence at lower temperatures (purple and green points). The frozen fractions retrieved from $\bar{g}$ for the 0.08 and $0.07 \mathrm{wt} \%$
Snomax droplets (not plotted, as they almost overlap with the solid red line) do not capture any of the freezing behavior measured indicating a very sensitive dependence of ice nucleating activity on surface area. A notable difference from the droplets containing illite is that there is significant weakening in ice nucleation ability as the concentration/surface area of Snomax is reduced. This behavior matches what is known regarding the low abundance of the most efficient but fragile Type I ice nucleating proteins that freeze at -3 to $-2{ }^{\circ} \mathrm{C}$ vs. the more abundant and resilient but less efficient Type III proteins that freeze around -8 to $-7^{\circ} \mathrm{C}$ (Polen et al., 2016; Turner et al., 1990; Yankofsky et al., 1981).

The freezing curves from droplets containing MCC cellulose powder (Hiranuma et al., 2015b) are shown in Fig. 7a. For the MCC cellulose freezing curves, $\bar{g}$ was found to have $\mu=1.63$ and $\sigma=0.12$, from the $0.1 \mathrm{wt} \%$ curve. The freezing curve retrieved from droplets containing $0.1 \mathrm{wt} \%$ (blue) cellulose was estimated to be the critical area transition value. While the second highest concentration freezing curve's $(0.05 \mathrm{wt} \%$, red) median freezing temperature is not captured by $\bar{g}$, the broadness of the curve is similar to that predicted by the model and the differences in the median freezing temperatures are within $1 \mathrm{~K}$. Assuming a surface area density of $1.44 \mathrm{~g} \mathrm{~m}^{-2}$ (Hiranuma et al., 2015a) the critical area for MCC cellulose is estimated to be around $\sim 9.4 \times 10^{-4} \mathrm{~cm}^{2}$. MCC cellulose appears to exhibit ice nucleating capabilities reasonably stronger than illite and significantly weaker than Snomax, based on the observed freezing temperature spectra and the $\bar{g}$ values retrieved. $\bar{g}$ for Snomax was $0.66 \pm 0.055,1.72 \pm 0.122$ for illite NX, as compared to $1.63 \pm 0.12$ for MCC cellulose.

To predict the freezing curves of the droplets with particle surface areas lower than the estimated critical area for the systems considered here, the aggregate surface area of the entire particle population within each droplet is modeled as 

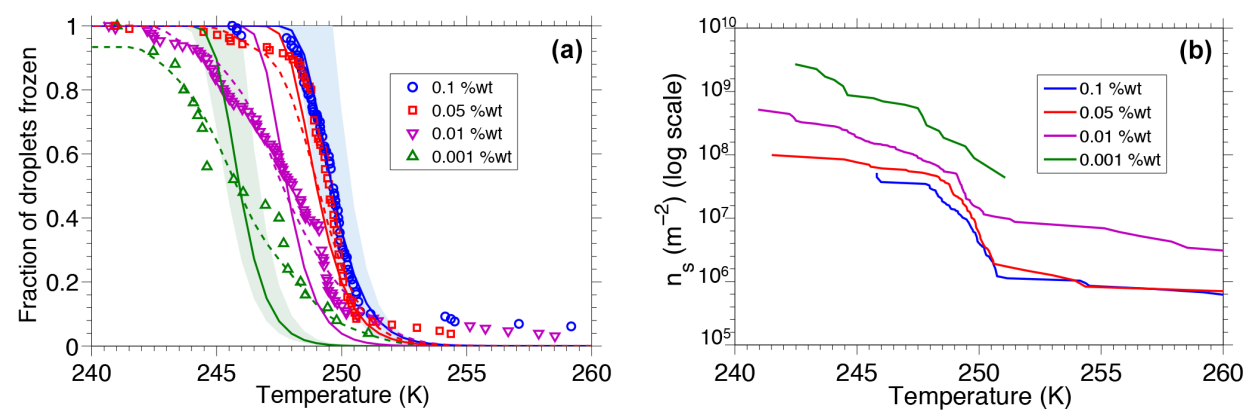

Figure 7. (a) Experimental freezing curves for different mass concentrations of MCC cellulose powder immersed in 500-700 $\mu \mathrm{m}$ diameter water droplets obtained using the CMU cold plate (circles). Dashed lines are fits produced from randomly sampling from the $\bar{g}$ distribution retrieved from the highest concentration freezing curve $(0.1 \mathrm{wt} \%$, blue solid line) and a surface area correction. The second highest concentration freezing curve $(0.05 \mathrm{wt} \%$, red) is used to confirm the critical area threshold was exceeded. The shaded region represents the effect of variability in surface area as in Fig. 5 but for a droplet diameter range of 500-700 $\mu \mathrm{m}$ for the highest and lowest particle concentration experiments. (b) Ice active site density $\left(n_{\mathrm{S}}\right)$ retrieved from the frozen fraction data on the left. A trend of increasing $n_{\mathrm{S}}$ with decreasing concentration is observed.

one large surface. A contact angle $\theta_{\mathrm{r}}$ is randomly selected from the full contact angle range $[0, \pi]$, and the value of the active site distribution $g^{*}$ for the particle $i$ being sampled at $\theta_{\mathrm{r}}$ is assigned the value of $\overline{g\left(\theta_{\mathrm{r}}\right)}$ :

$\left(g_{i}^{*}\left(\theta_{\mathrm{r}, n_{\text {draw }}}\right)\right)=\overline{g\left(\theta_{\mathrm{r}}\right)}$.

The $g^{*}$ distributions within this numerical model are given an asterisk to indicate that they are discrete distributions.

This process is repeated for a parameter $n_{\text {draws }}$, for each droplet in the array that produced the freezing curve being modeled. $n_{\text {draws }}$ is the only parameter that is optimized so the modeled freezing curves can predict the behavior of the experimental freezing curves. The value of $n_{\text {draws }}$ typically ranges from 9 to 65 for the systems analyzed here and is therefore a relatively soft optimization parameter with small dynamic range. The sampled $g^{*}$ distributions are normalized with respect to the estimated total surface area for the freezing curve being modeled before being used to compute the freezing probability. The bottom part of Fig. 4 shows a schematic of how $g^{*}$ is retrieved from $\bar{g}$ using $n_{\text {draws }}$. With the sampled $g^{*}$ distributions the freezing probability of each droplet is calculated using Eq. (9) and the frozen fraction curve is computed from the arithmetic average of the freezing probabilities:

$F($ below critical area $)=\frac{1}{N} \sum_{i=1}^{N} P_{\mathrm{f}_{i}}$,

where $N$ is the number of droplets in the cold plate array.

The behavior of the experimental curve is captured using the $n_{\text {draws }}$ numerical model in which random sampling from the ice nucleating spectrum dictated by $\bar{g}$ is carried out to predict the freezing curve. The dotted lines in Figs. 5, 6a, and $7 \mathrm{a}$ are obtained by sampling from the $\bar{g}$ model to successfully predict the behavior of all the freezing curves. The early freezing onsets of the lower concentration systems as well as the broadness in the curves are both captured with the model. After $\bar{g}$ was obtained from the high concentration data above the critical area threshold, the only parameter that had to be optimized to produce these accurately predicted freezing curves was $n_{\text {draws }}$. The values of $n_{\text {draws }}$ for the lower concentration freezing curves for each of the systems investigated here are $21\left(2.02 \times 10^{-6} \mathrm{~cm}^{2}\right), 19\left(1.04 \times 10^{-6} \mathrm{~cm}^{2}\right)$, and $11\left(7.11 \times 10^{-7} \mathrm{~cm}^{2}\right)$ for the droplets containing illite; $65(0.09 \mathrm{wt} \%), 48(0.08 \mathrm{wt} \%)$, and $23(0.07 \mathrm{wt} \%)$ for the droplets containing Snomax; and $21(0.05 \mathrm{wt} \%), 11$ $(0.01 \mathrm{wt} \%)$, and $9(0.001 \mathrm{wt} \%)$ for the droplets containing cellulose. It should also be noted that there is an $n_{\text {draws }}$ value for each system above for which the sampled distribution mimics $\bar{g}$. For example, when $n_{\text {draws }}$ is 25 for the illite system, the retrieved distribution will produce a freezing curve equivalent to using $\bar{g}$.

Perhaps the most notable characteristic is how the freezing curves of all three systems analyzed ascend together early as temperature is decreased but then diverge as the temperature decreases further (Figs. 5, 6a, and 7a). The closeness of the data at warmer temperatures (the ascent) is interpreted by the framework as the continued presence of smaller contact angles (stronger active sites) within the $g^{*}$ distributions of some of the particles under all the particle concentrations explored in these experiments. Due to the strength of the ice nucleating activity at small contact angles, a smaller number of draws is required to capture this region of the contact angle range than the lower activity described by the larger contact angles. This results in a greater diversity in the larger (weaker) contact angles between the particles and is how the model successfully captures the increasing external variability with decreasing surface area. In a later section, the claim of more external variability contributing to the broader curves below the critical area threshold is supported with a closer look at the numerical results from the model. 
The droplets containing Snomax displayed an immediate shift in freezing behavior for small changes in concentration (from 0.1 to $0.09 \mathrm{wt} \%$ ) whereby a small drop in concentration, and thus surface area, resulted in a broader temperature range over which freezing of the droplets occurred (Fig. 6a). In the context of the model presented here, this is due to the mode of the $\bar{g}$ distribution occurring at a very small (and thus very active) contact angle of 0.66 . In this contact angle range, the barrier to nucleation is greatly reduced causing freezing to be even more sensitive to the strongest active sites, and less sensitive to the competing active sites that are weaker but more abundant (depicted in Fig. 2), and therefore causing freezing curves to be quite steep vs. $T$. A small change in the surface area of this material may have produced a significant reduction in the probability of droplets possessing this very strong range of ice nucleating activity, resulting in the observed broadening of the freezing curves. This trend in Snomax is further investigated numerically in a following section.

Figure 4 also plots the popular, exclusively deterministic scheme's ice active site density parameter $n_{\mathrm{s}}$ (Hiranuma et al., 2015a; Murray et al., 2012; Vali, 1971, 2008; Wex et al., 2015). $n_{\mathrm{s}}$ is an active site density function defined in the following equation:

$F=1-\exp \left(-n_{\mathrm{S}}(T) A\right)$.

Equation (18) is similar in mathematical form to Eq. (15) and inherently assumes that active site density can be defined as uniform over a particle's surface and is therefore independent of the total surface area (it is multiplied by total surface area to estimate total heterogeneous ice nucleation activity). From this point on, $n_{\mathrm{s}}$ is regarded as the deterministic analog of $\bar{g}$, where any time-dependent (stochastic) freezing is omitted. The justification presented for the definition and use of the critical area quantity also applies to the $n_{\mathrm{s}}$ framework, where it is argued that $n_{\mathrm{s}}$ ceases to become a proper representation of the ice nucleation activity below the critical area threshold.

The values of $n_{\mathrm{s}}$ were retrieved directly from freezing curves of droplets with illite particles immersed in them, measured in a cold plate system by Broadley et al. (2012) and used to produce Fig. 4b. As the total particle surface area of the system under study is reduced from the blue to the red curve, the retrieved $n_{\mathrm{s}}$ values are similar, indicating that variability of active sites remains constrained within droplets. Note that both the red and blue curves were obtained from systems we have determined were above the critical area threshold (Fig. 4). Further reduction of total surface area to below the critical area threshold shifts the $n_{\mathrm{s}}$ values noticeably, as seen by the significant increase in $n_{\mathrm{S}}(T)$ for the green curve. As all three curves were obtained by just varying the particle concentration of the same species, the same $n_{\mathrm{s}}$ values should be retrieved for all three curves at each temperature; the $n_{\mathrm{s}}$ scheme is designed to normalize for the total surface area or particle mass $\left(n_{\mathrm{m}}\right)$ present. This is successful for the higher particle surface area systems (red and blue curves are similar) but not at lower particle area (green curve diverges). The large increase in $n_{\mathrm{s}}$ observed when total surface area is below the critical area threshold indicates that the observed droplet freezing temperature spectra do not just linearly scale with particle concentration or surface area. Further analysis will show this is not due to an enhancement of ice nucleating activity per surface area but is actually the random sampling process redistributing smaller and larger contact angles in such a way that some particles now have higher ice nucleating activity per surface area while others have a weaker ice nucleating activity per unit surface area. This is regarded as an increase in the external variability of the system.

We have observed other similarly large effects of particle concentration on the measured droplet freezing temperature spectrum and the retrieved $n_{\mathrm{s}}$ curves from our own cold plate measurements. Figures $6 \mathrm{~b}$ and $7 \mathrm{~b}$ display $n_{\mathrm{m}}$ (active site density per unit mass; Wex et al., 2015) and $n_{\mathrm{s}}$ curves vs. temperature for freezing droplets containing Snomax and MCC cellulose, respectively. Similar to the data in Fig. 4b, these two systems also exhibit a divergence in $n_{\mathrm{s}}$ (or $n_{\mathrm{m}}$ ) as concentration (or surface area) is decreased. Droplets containing MCC cellulose exhibited a much stronger sensitivity to decreasing surface area than the droplets containing illite, with changes in the values of $n_{\mathrm{s}}$ of up to 4 orders of magnitude. The droplets containing Snomax, on the other hand, were less sensitive to changes in surface area and exhibited an opposite trend in $n_{\mathrm{m}}$, with the values of $n_{\mathrm{m}}$ decreasing with decreasing concentration. This is consistent with the analysis of the Snomax freezing curves, where the ice nucleating activity experienced a substantial drop with decreasing surface area. It is further argued in a later section that this is due to the very sharp active site density function $g$ that Snomax particles appear to possess, resulting in steep droplet freezing temperature curves.

In assessing the three systems investigated here, it appears that the critical area threshold depends a lot on the strength $(\overline{g(\theta)})$ of the ice nucleating activity for that system. Capturing the critical area transition for illite required probing droplets that were an order of magnitude smaller than the droplets containing Snomax and cellulose, indicating a very large difference in the scale of the critical area. One explanation for this behavior is that when ice nucleating activity is weak, nucleation can occur over a larger total nucleating surface area. This means there is a smaller chance of losing critical active sites in a droplet as the amount of material is reduced with decreasing particle concentration. This argument is supported by these three datasets that span almost the entire heterogeneous ice nucleation temperature range.

For the illite mineral suspensions, Broadley et al. (2012) identified two total surface area regimes by analyzing their droplet freezing curves. In the lower surface area regime, they observed a different freezing dependence on particle surface area than at higher surface areas. At higher surface areas they saw no dependence of the freezing curves on total particle surface area, which is inconsistent with both the 
stochastic and deterministic frameworks. For larger droplets, the transition seemed to occur at higher total particle surface area, indicating that there might be a particle concentration effect impacting the total particle surface area per droplet. We have conducted our own illite measurements on the same mineral sample used by Hiranuma et al. (2015a) (Arginotec, NX nanopowder) to investigate this high concentration regime and further probe the applicability of $\bar{g}$ to freezing curves above the identified critical area threshold. Figure 8 shows the frozen fractions vs. temperature for an ensemble of droplets containing illite NX on our cold plate system. The concentrations used were $0.5,0.3,0.25,0.2$, $0.1,0.05,0.03,0.01$, and $0.001 \mathrm{wt} \%$ and the droplets were cooled at a rate of $1 \mathrm{~K} \mathrm{~min}^{-1}$. Average surface area estimates are made by assuming $600 \mu \mathrm{m}$ diameter droplets and a surface area density of $104 \mathrm{~m}^{2} \mathrm{~g}^{-1}$ (Broadley et al., 2012). The solid lines are applications of Eq. (15) with the same $\bar{g}$ as the one found for the illite dataset considered above. It can be seen that this $\bar{g}$ retrieved from cold plate experiments where droplets are on the order of $10-20 \mu \mathrm{m}$ produces reasonable predictions of the freezing curves where droplets are on the order of $600 \mu \mathrm{m}$ and thus contain particle surface areas up to 5 orders of magnitudes larger. Another important conclusion that can be drawn from this dataset is that high concentration data $(0.25,0.3$, and $0.5 \mathrm{wt} \%)$ exhibited a similar plateauing in freezing temperatures despite additional amounts of illite. This is similar to the concentration range where Broadley et al. (2012) found a saturation effect when further increasing the concentration of illite (over $0.15 \mathrm{wt} \%$ ). The fact that the concentration where this saturation effect is so similar while the droplet volumes and consequently the amount of illite present between the two systems is quite different points to a physical explanation such as particle settling or coagulation due to the very high occupancy of illite in the water volume. These physical processes could reduce the available particle surface area in the droplet for ice nucleation. Additionally, the high concentration freezing curves show a good degree of broadening in the temperature range over which freezing occurs. These three curves share a close $50 \%$ frozen fraction temperature (with the $0.5 \mathrm{wt} \%$ oddly exhibiting a slightly lower $50 \%$ frozen fraction temperature than the other two). One explanation that is consistent with the hypothesis of particle settling and coagulation is that it becomes less likely that the droplets contain similar amounts of suspended material when they are generated from such a concentrated suspension (Emersic et al., 2015). This results in larger discrepancies in available surface area between the droplets and therefore a broader temperature range over which the droplets are observed to freeze.

One final thing to note is that the mathematical analysis presented here ignores the variability in total particle surface area present between droplets in each experiment. According to the range of droplet diameters mentioned in the Broadley et al. (2012) data of 10-20 $\mu \mathrm{m}$, surface area variability between the smallest and largest droplets in the experiment can

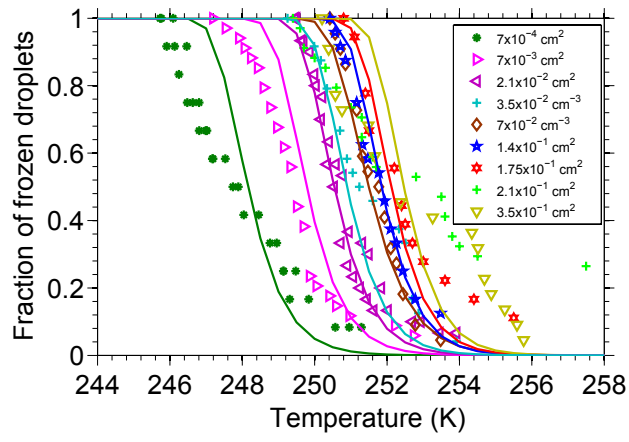

Figure 8. Experimental freezing curves for different mass concentrations of illite NX powder immersed in 500-700 $\mu$ m diameter water droplets obtained using the CMU cold plate (circles). The solid lines are the predicted frozen fractions based on the $\bar{g}$ distribution retrieved from the Broadley et al. (2012) data and a surface area correction. A concentration saturation effect appears to be present, whereby the blue, red, and gold experimental data points overlap despite being at different concentrations.

be as high as a factor of 8 . While for the data presented from the Carnegie Mellon University (CMU) cold plate with droplet diameter varying from $500-700 \mu \mathrm{m}$, variability can be as high as a factor of 5. This assumes that the particle concentration is the same in each droplet, as they were produced from well-mixed particle suspensions in water. This surface area variability can be the source of an alternative explanation to the broadness of the freezing curves, whereby an analysis along the lines of what is presented in Alpert and Knopf (2016) can be applied.

The shaded regions of Figs. 5, 6a, and 7a show the predicted temperature range over which freezing of droplets occurs for the surface area variability associated with the diameter range of the considered experiments using $\bar{g}$ (i.e., running Eq. 9 with different values for $A$ ). Figures 5 and 7 a show the predicted freezing variability for the highest and lowest mass concentrations while Fig. 6a only shows it for the highest concentration as the range predicted for the lowest concentration almost completely overlaps with the highest concentration. The prediction from surface area variability does contain the temperatures over which droplets freeze for the high concentration freezing curve but falls short of capturing the range for the low concentration freezing curve. More importantly, while the scatter in surface area between droplets can explain some of the broadness in the freezing curves, it is unable to explain why the curves become broader in the temperature range they span with decreasing surface area. Freezing temperature should respond linearly to surface area, if no other factors are changing (Eq. 9). This observed trend is quite repeatable; according to Broadley et al. (2012) freezing temperatures were reproducible to within $1 \mathrm{~K}$ for their illite measurements, while for the CMU experiments for illite, MCC cellulose, and Snomax, the difference in freezing temperature spectra between at least two replicate experiments 
did not exceed $1 \mathrm{~K}$. Therefore, if surface area scatter alone is proposed to explain the increasing variability of freezing temperatures with decreasing concentration/surface area, a cause for an increase in surface area scatter with decreasing concentration would have to be hypothesized. We recognize that such a surface area variability approach is also a viable one but the framework presented here presents an increase in the variability in ice nucleation activity with decreasing concentration/surface area as the means for describing the observed trends.

\subsection{Comparison between $\bar{g}, n_{\mathrm{s}}$, and other existing parameterizations of heterogeneous ice nucleation}

To our knowledge, this is the first heterogeneous ice nucleation parameterization that aims to attribute a surface area dependence to active site distributions of INPs. The popular, exclusively deterministic scheme (Broadley et al., 2012; Murray et al., 2012; Vali, 1994, 2008; amongst others) prescribes an ice active site density function $n_{\mathrm{s}}$ that is an intensive property of the species under study. Equation (15), derived from classical nucleation theory and used in the $\bar{g}$ model, and the deterministic-based Eq. (18) used in the $n_{\mathrm{s}}$ model, have a very close mathematical form. Both carry a negative exponential dependence on surface area, and the temperature dependence in the rest of the variables is inside the exponent.

Fitting freezing curves with droplets below the critical area threshold with $n_{\mathrm{s}}$ yields errors similar to fitting the curves with $\bar{g}$. Doing so has an inherent assumption of the ice nucleation activity being totally internally variable. This is clear in comparing Eqs. (15) and (18). That is, $\bar{g}$ and $n_{\mathrm{s}}$ both offer incomplete information about the distribution of ice nucleation activity for a species. A similar conclusion along these lines was reached by Broadley et al. (2012) when the authors noted that the best fits to their freezing curves at low concentrations were achieved when the system was assumed to be totally externally variable. That is, when each particle was assumed to have a single contact angle but a distribution assigned a spectrum of contact angles for each particle in the population.

There are other formulations that hypothesize an activesite-based or multicomponent stochastic model such as the ones described in Vali and Stransbury (1966), Niedermeier et al. (2011), Wheeler and Bertram (2012), and Wright and Petters (2013). Vali and Stransbury (1966) were the first to recognize that ice nucleating surfaces are diverse and stochastic, and thus active sites need to be assigned both a characteristic freezing temperature as well as a variability parameter around that temperature. Niedermerier et al. (2011) proposed the soccer ball model, in which a surface is partitioned into discrete active sites with each site conforming to classical nucleating theory. Marcolli et al. (2007) found a Gaussian distribution of contact angles could best describe their heterogeneous ice nucleation data in a completely de- terministic framework. Welti et al. (2012) introduced the alpha-PDF model where a probability density function prescribes the distribution of contact angles that a particle population possesses, such that each particle is characterized by a single contact angle. Wright and Petters (2013) hypothesized the existence of a Gaussian probability density function for a specific species, which in essence is similar to the $\bar{g}$ framework described here. The notable difference is that their probability density function was retrieved via optimizing for all freezing curves, and not from independently fitting high concentration freezing curves as we have done here. Alpert and Knopf (2016) present a single-component stochastic framework but successfully describe freezing behavior by considering surface area variability, more specifically defining a distribution of surface areas material in different droplet exhibits. A distribution of particle surface areas can provide a similar basis for variability in freezing temperatures between different particle-containing droplets as a distribution of ice nucleating activity.

The $n_{\mathrm{s}}$ scheme is now more commonly used to describe and compare cold plate and other experimental ice nucleation data instead of the multicomponent stochastic schemes (Hiranuma et al., 2015a; Hoose and Möhler, 2012; Murray et al., 2012; Wex et al., 2015). This is in part due to the necessary inclusion of more variables required by other frameworks (such as prescribing a discrete number of active sites in the soccer ball model by Niedermeier et al., 2011) than the simpler purely deterministic scheme of $n_{\mathrm{s}}$. The new formulation described here requires only prescribing a species' heterogeneous ice nucleation ability as a function $\bar{g}$ along with finding the critical area, $A_{\mathrm{c}}$, and $n_{\text {draws }}$. The critical area is determined by repeatedly measuring freezing curves for the same system or sample using different particle concentrations. Varying particle concentration is already routinely used in cold plate experiments to widen the droplet freezing temperature range that can be measured. An estimate of the total surface area of the particles under study must be made and associated with the retrieved freezing curves. While a process of random sampling using $n_{\text {draws }}$ is initially necessary to predict the freezing curves at more atmospherically realistic concentrations below the critical area, in a following section we will introduce easy-to-apply parameterizations that convert frozen fractions for surface areas larger than the critical area to frozen fractions for surface areas smaller than the critical area.

\subsection{Dependence of $g$ on INP size}

The particle size dependence of the freezing probability comes from the exponential dependence of the freezing probability on the surface area $A$ as shown in Eq. (7). The freezing probability's sensitivity to surface area is the same as its sensitivity to time; however, the quadratic dependence of area on radius makes size a more sensitive parameter than time. Furthermore, there might be more subtle size depen- 
dencies in the $g$ function itself. For a given particle type, whether size affects the diversity (internal variability) of nucleating sites is not something that can be trivially probed experimentally. To accurately test any potential size dependence, particles of varying sizes need to be probed individually and compared. Measurements in which particles were size selected before assessing their ice nucleation ability have been performed, such as those using continuous flow diffusion chambers as described in Koehler et al. (2010), Lüönd et al. (2010), Sullivan et al. (2010a), Welti et al. (2009), among others. However, a similar limitation to the cold plate experiments presents itself in which the freezing onsets of many droplets containing a range of particle sizes are averaged to find a frozen fraction curve. The resultant curves have potential internal and external variability embedded, with not enough information to disentangle them. Hartmann et al. (2016) recently investigated the impact of surface area on active site density of size-selected kaolinite particles by probing three different particle diameters. They concluded that kaolinite ice nucleating activity did not exhibit size dependence, similar to the trends reported here. However, a different mineral species was investigated than the illite we focus on here, and they probed a very different size range than in our experiments. We therefore think that our results provide incentive to pursue more of the quite insightful experiments presented by Hartmann et al. (2016) where particle size is varied over a large range.

The argument for the existence of a species' specific critical area can be made for either a total number of particles in a specific size range or a total particle surface area. Assuming that a single species' surface area does not undergo intensive changes in its ice nucleation properties (such as chemical processing as discussed in Sullivan et al., 2010a, b) a cut-off critical size can be defined. Above this critical size, the active site distribution is $\bar{g}$ while below it is some distribution of $g$ that can be sampled from $\bar{g}$. In one of the cases studied here in Fig. 5, the critical surface area was around $10^{-6} \mathrm{~cm}^{2}$ for illite mineral particles. This corresponds to a single spherical particle with an equivalent diameter of around $10 \mu \mathrm{m}$, a size cutoff that is quite atmospherically relevant (DeMott et al., 2010). The vast majority of the atmospheric particle number and surface area distributions are found at sizes smaller than $10 \mu \mathrm{m}$. Thus, we conclude that for illite mineral particles, individual atmospheric particles will not contain the entire range of ice active site activity $(\bar{g})$ within that one particle, and each particle's ice nucleation ability is best described by an individual $g$ distribution (that is a subsample of $\bar{g}$ ).

Application of Eq. (11) to find $A_{\text {nucleation }}$ for illite systems $6 \mathrm{a}\left(2.02 \times 10^{-6} \mathrm{~cm}^{2}\right)$ and $5 \mathrm{a}\left(1.04 \times 10^{-6} \mathrm{~cm}^{2}\right)$ from Broadley et al. (2012) gives insight into how the nucleating area is influencing the shape of the freezing curves. System $6 a$ is where the critical area cutoff was found to occur while 5a started to exhibit the behavior of a broader freezing curve with a similar onset of freezing, indicating it is below the critical surface area. In Fig. 9, the average cumulative ice

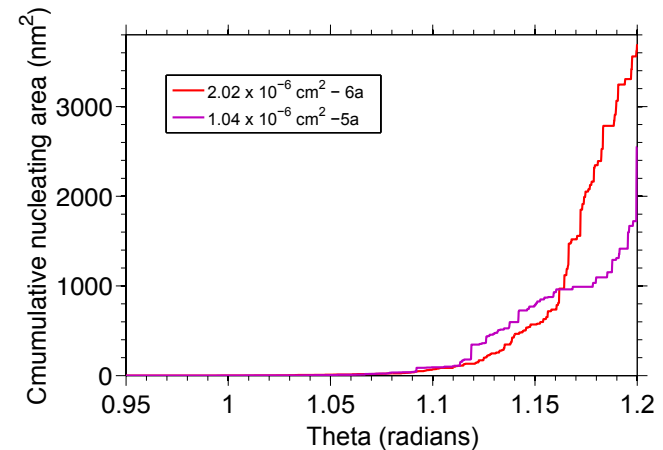

Figure 9. Cumulative ice nucleating surface areas from application of Eq. (11) to modeled average $g$ distributions from systems 6 a (red) and 5a (purple) in Fig. 5, taken from cold plate measurements of illite in droplets from Broadley et al. (2012), plotted against the critical contact angle range. At low contact angles the two systems have close total nucleating surface areas. This explains the similar onset of freezing before the eventual divergence at lower temperature (larger contact angle).

nucleating area computed from Eq. (11) is plotted against the critical contact angle range for the two systems. In examining the cumulative nucleating areas, two regions can be identified. The first region ( $0.95 \mathrm{rad}$ to $1.15 \mathrm{rad}$ ) includes the stronger active sites that contribute to the earlier warmer regions of the freezing curves, while the second region (1.15 to $1.2 \mathrm{rad}$ ) contributes to the tail and colder end of the freezing curves. The first region is broader in contact angle range but smaller in total nucleating area. Therefore, statistically there is a higher chance of particles of smaller area to draw these contact angles in the random sampling process. The second region is narrower in the critical contact angle range but occupies a larger fraction of the total nucleating area. Therefore, more draws are necessary to replicate the nucleating behavior of this region, and thus there is a stronger drop-off in the nucleating area represented by these less active contact angles as the surface of the particles is reduced.

This helps to explain why the onset of freezing for the two curves is so similar. The diverging tail can be attributed to the divergence of the nucleating areas at higher contact angles in the critical contact angle range. The steeper rise of the average nucleating area of system $6 \mathrm{a}$ is due to its greater chance of possessing active sites characterized by the second region of the critical contact angle range compared to system 5a due to the larger surface area present in 6a. This creates a larger spread in the freezing onset of droplets in system 5a after a few droplets initiated freezing in a similar manner to system $6 \mathrm{a}$.

A similar nucleating area analysis was performed on the droplets containing Snomax and is shown in Fig. 10. The cumulative nucleating areas for the droplets with Snomax concentrations of 0.09 and $0.08 \mathrm{wt} \%$ (red and purple data in Fig. 6, respectively) are calculated and shown over the crit- 


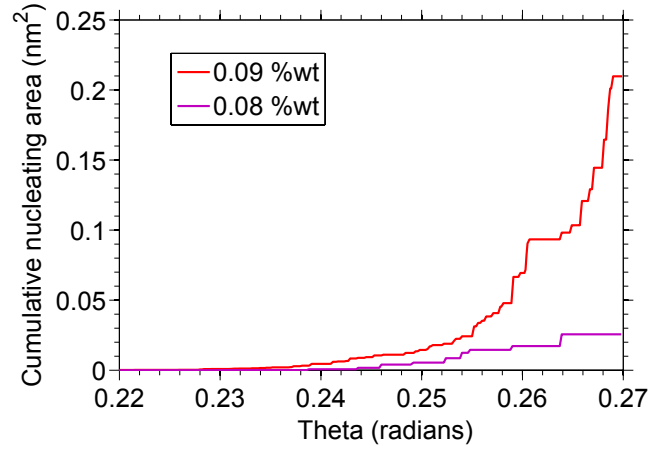

Figure 10. Cumulative ice nucleating surface areas from application of Eq. (11) to modeled average $g$ distributions from droplets containing $0.09 \mathrm{wt} \%$ Snomax (red) and $0.08 \mathrm{wt} \%$ Snomax (purple) in Fig. 6 plotted against the critical contact angle range. This system does not exhibit similar nucleating areas at low contact angles and thus does not show an increase in $n_{\mathrm{S}}$ with decreasing concentration (or surface area).

ical contact angle range with the same color scheme. Unlike the illite system, droplets containing Snomax exhibit a more straightforward trend in cumulative nucleating area vs. critical contact angle. The cumulative nucleating area is consistently smaller in the $0.08 \mathrm{wt} \%$ system compared to the $0.09 \mathrm{wt} \%$ experiment, indicating that as the particle surface area is reduced the strong nucleators are reduced uniformly over the critical contact angle range. This supports the idea that the range of ice nucleating activity is much smaller for this very ice active system. The consistent decline in nucleating area is attributable to the very narrow critical contact angle range the nucleating area covers (only $0.05 \mathrm{rad}$ ). We propose that this is what explains the decrease in $n_{\mathrm{m}}$ with decreasing concentration observed in Fig. 6. We stress however that this explanation is not physical and is merely a mathematical interpretation of the experimental trend being observed.

The implication of this analysis on the size dependence of $g$ is that below the critical surface area particles may or may not possess freezing behavior similar to the particles above the critical area threshold. The broadening of the freezing curves in the systems analyzed here as the surface area is reduced is interpreted as heterogeneity in ice nucleating ability between the different particles (external variability) and not due to the internal variability within the individual particles themselves. While the broadness of the curves above the critical surface area can be attributed to internal variability, the additional broadness in curves below the critical area cutoff are a result of external variability.

More detailed analysis studying various atmospherically relevant INPs needs to be done to shed light on whether a particle size cutoff corresponding to a critical area threshold can be used to describe the behavior of different species. This has important implications on whether one active site density function (i.e., $\bar{g}$ or $n_{\mathrm{s}}$ ) is sufficient to accurately represent the species' ice nucleating properties in cloud or atmospheric models. If not, a more detailed parameterization resolving the multidimensional variability may be necessary, such as a series of $g$ distributions. For illite it seems that external variability is dominant, and thus one active site distribution or $n_{\mathrm{s}}$ parameterization does not properly represent the species' ice nucleation behavior. The critical area effect is even more substantial for cellulose and Snomax, as their ice nucleating activity is much stronger than illite. However, if a system's global $\bar{g}$ distribution is obtained then its full ice nucleation behavior is contained within and can be successfully subsampled from $\bar{g}$.

Cold plate experimental data potentially provides sufficient information to describe heterogeneous ice nucleation properties in cloud parcel and atmospheric models; however, the analysis undertaken here suggests that retrieving one active site density parameterization (e.g., $n_{\mathrm{s}}$ ) and applying it to all surface areas can result in misrepresenting the freezing behavior. When samples are investigated, probing a wide concentration range enables the determination of both general active site density functions (e.g., $\bar{g}$ ) as well as the behavior of the species' under study at more atmospherically relevant concentrations below the critical area threshold. Once this analysis is undertaken more comprehensive parameterizations can be retrieved as will be developed in the next section.

The critical area analysis therefore emphasizes the dangers in extrapolating the freezing behavior of droplets containing a large concentration of particles to droplets containing smaller concentrations or just individual particles. Applying a parameterization such as $n_{\mathrm{s}}$ directly to systems below the critical area threshold in a cloud parcel model, for example, yields large differences in the predictions of the freezing outcome of the droplet population. As the concentration of the species within the droplets was decreased in the cold plate freezing spectra considered here, the actual freezing temperature curves diverged more and more from those predicted when the systems were assumed to be above the critical area. This led to significant changes in the retrieved $n_{\mathrm{s}}$ values, as shown in Figs. 4b, 6b, and 7b. The large effects of concentration on the droplet freezing temperature can be directly observed in the frozen fraction curves plotted in Figs. 5, 6a, and $7 \mathrm{a}$. Differences between observed frozen fraction curves and ones that assumed uniform active site density yielded errors in the temperature range that the droplets froze over as well as the median droplet freezing temperature. Therefore, a cloud parcel model would be unable to accurately predict the freezing onset or the temperature range over which freezing occurs using a single $n_{\mathrm{s}}$ curve obtained from high concentration data. This has important consequences for the accurate simulation of the microphysical evolution of the cloud system under study, such as the initiation of the WegenerBergeron-Findeisen and the consequent glaciation and pre- 
cipitation rates (Ervens et al., 2011; Ervens and Feingold, 2012).

Figure 11 shows the range of $n_{\mathrm{s}}$ values for illite NX mineral compiled from 17 measurement methods used by different research groups, the details of which are described by Hiranuma et al. (2015a). The range of data is summarized into shaded sections to separate suspended droplet freezing techniques (such as a cold plate) from techniques where the material under investigation is aerosolized before its immersion freezing properties are assessed (such as the CFDC or AIDA cloud expansion chamber). The aerosol techniques tend to produce higher retrieved $n_{\mathrm{s}}$ values than those obtained by the wet suspension methods. $n_{\mathrm{s}}$ data spanning a surface area range of about 5 orders of magnitude retrieved exclusively from both our cold plate measurements and Broadley et al. (2012) measurements are also plotted. Data presented in Fig. 8 that was consistent with a $\bar{g}$ treatment is plotted as $n_{\mathrm{s}}$ (described in the CMU column in Fig. 11). This dataset along with what was identified as freezing data past the critical area threshold from the Broadley et al. (2012) experiments follow a consistent $n_{\mathrm{S}}$ line that lies within the range of the suspended droplet techniques. The blue triangles are low surface area data points retrieved from dataset $4 \mathrm{a}$ from the Broadley et al. (2012) measurements. As was argued earlier, this system exhibits higher $n_{\mathrm{s}}$ values, an artifact of the increased active site density of some of the particles. While these data are retrieved with a cold plate, it falls within the range of the aerosolized methods where particle surface areas are small. Finally, more of the suspension method range of retrieved $n_{\mathrm{s}}$ can be spanned by data where the concentration saturation effect takes place. Data that exhibited this behavior from the CMU cold plate system (golden triangles) and the Broadley et al. (2012) system (red and brown bow ties) are plotted. This effect tends to underestimate $n_{\mathrm{S}}$ since additional material is added while the freezing behavior remains the same. Thus, just by varying particle concentration and surface area of illite in the droplets, cold plate measurements can span the range of $n_{\mathrm{s}}$ values obtained by the various aerosol and wet suspension measurement methods. We emphasize again than $n_{\mathrm{s}}(T)$ should be the same for the same system, and this metric is often used as the major means to compare and evaluate different INP measurement methods.

Various research groups using wet suspension methods typically vary particle concentrations to span a wider range of measurable droplet freezing temperature (Broadley et al., 2012; Murray et al., 2012; Wright and Petters, 2013). Our analysis indicates that by doing so different $n_{\mathrm{s}}$ values are in fact retrieved, just due to changes in concentration. This highlights the importance of obtaining $n_{\mathrm{s}}$ values that overlap in temperature space, to evaluate if $n_{\mathrm{S}}$ is in fact consistent as concentration is changed. We therefore provide the critical area framework presented here whereby ice nucleating surface area dependence is more complex than depicted in traditional deterministic and stochastic models, as a potential source of the discrepancy in $n_{\mathrm{s}}$ values for the various mea-

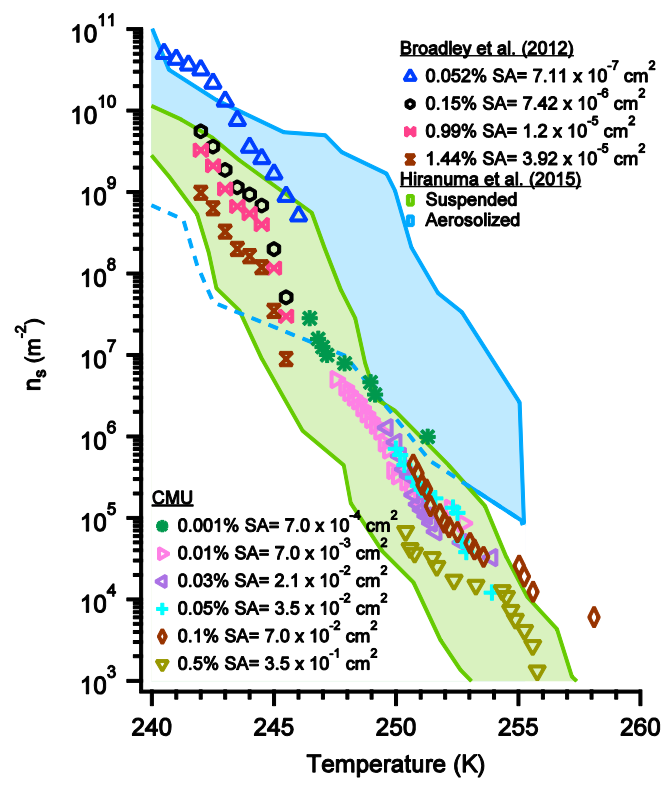

Figure 11. Range of $n_{\mathrm{S}}$ values for illite NX mineral dust compiled from 17 measurement methods used by different research groups, the details of which are described by Hiranuma et al. (2015a). The range of data is summarized into shaded sections to separate suspended droplet techniques (such as the cold plate) from techniques where the material under investigation is aerosolized before immersion freezing analysis. Data from both the Broadley et al. (2012) and the CMU cold plate systems are also plotted to show how much of the range can be spanned via the critical area effect (blue triangles) and the concentration saturation effect (purple hexagons and red and brown bow ties).

surement techniques. This commonly observed discrepancy in $n_{\mathrm{s}}$ between droplet suspension and aerosol INP measurement methods is the subject of ongoing investigations, such as the INUIT project that is currently focusing on cellulose particles, a system we have included here. As the results from this multi-investigator project have not yet been published, we cannot present them here. They show a similar trend as for the illite NX data, where the aerosol methods retrieve higher $n_{\mathrm{S}}$ values than the droplet suspension methods. By changing particle-in-droplet concentration, we can span much of the difference in $n_{\mathrm{s}}$ between the two groups of methods, as was shown for the illite NX measurements.

\section{Application of the $g$ parameterization to cloud models}

Particle-type-specific $\bar{g}$ distributions and critical areas can be used in larger cloud and atmospheric models to predict freezing onset and the rate of continued ice formation. The simplest parameterization is one that calculates the frozen fraction of droplets, $F$, for an atmospherically realistic system in which one INP is present in each supercooled droplet, 
the aerosol particle distribution is monodisperse (all particles therefore have the same surface area $A$ ), there is only one species present (therefore one $\bar{g}$ distribution is used), and the surface area of the individual particles is larger than that species' critical area. In this case, Eq. (15) can be used:

$F=1-\exp \left(-t A \int_{0}^{\pi} J(\theta, T) \overline{g(\theta)} \mathrm{d} \theta\right)$.

If the surface area of the individual particles is smaller than the critical area, a modified version of Eq. (19) can be used instead:

$F=1-\exp \left(-t A_{\mathrm{c}} \int_{0}^{\pi}(J(\theta, T) \overline{g(\theta)} \mathrm{d} \theta) h(A, T)\right)$,

where $h(A, T)$ is an empirically derived parameterization that corrects for the individual particle surface areas of the considered monodisperse aerosol population being smaller than the critical area. Therefore, $h\left(A_{\mathrm{c}}, T\right)=1$.

An example of retrieving values of $h(A, T)$ would be in correcting the solid line for system $4 \mathrm{a}\left(7.11 \times 10^{-6} \mathrm{~cm}^{2}\right)$ to the dotted line in Fig. 5. The solid line is the basic use of Eq. (15); however, it was shown that the considered experimentally retrieved freezing spectrum was below the critical area threshold. By taking the ratio of the dotted and solid lines, values of $h$ can be retrieved for that surface area at each temperature point.

If the aerosol particle population is polydisperse and its size distribution can be expressed as a function of surface area, the frozen fraction can be written as

$$
F=\int_{A_{i}}^{A_{f}}\left[1-\exp \left(-t A \int_{0}^{\pi}(J(\theta, T) \overline{g(\theta)} \mathrm{d} \theta) h(A, T)\right)\right] \mathrm{d} A
$$

where $A_{i}$ and $A_{f}$ are the minimum and maximum values of the surface areas of the aerosol particle distribution.

If the aerosol ice nucleating population is composed of multiple species, two $\bar{g}$ parameterizations can be formulated for the two cases of an internally mixed (every particle is composed of all the different species) and externally mixed (every particle is composed of just one species) system. For the case of an internally mixed system, Eqs. (15), (19), and (20) can be applied with a $\bar{g}$ distribution that is the surface area weighted average of the $\bar{g}$ distributions of all the considered species. This can be expressed as

$\bar{g}_{\text {average }}=\frac{1}{A} \sum_{i=1}^{m} A_{i} \bar{g}_{i}$,

where $A_{i}$ is the surface area of the species $i, \bar{g}_{i}$ is the $\bar{g}$ distribution of the species $i$, and $m$ is the total number of species. If the system is externally mixed, the frozen fraction can be expressed as

$F=\frac{1}{m} \sum_{i=1}^{m} F_{i}$

where $F_{i}$ is the frozen fraction of droplets containing particles of species $i$ and can be retrieved from Eqs. (19) or (20).

\section{Conclusions}

Cold plate droplet freezing spectra were carefully examined to investigate a surface area dependence of ice nucleation ability whereby one active site density function such as $n_{\mathrm{S}}$ cannot be extrapolated from high particle surface area to low particle surface area conditions. A method based on the notion of a critical surface area threshold was presented. It is argued that a species' entire ice nucleating spectrum can be confined within a global probability density function $\bar{g}$. For a system, be it one particle or an ensemble of particles, to have a total surface area greater than the critical area is a question of whether the surface is large enough to express all the variability in that particle species' ice active surface site ability. By analyzing droplets containing illite minerals, MCC cellulose, and commercial Snomax bacterial particles, it was shown that freezing curves above a certain critical surface area threshold could be predicted directly from the global $\bar{g}$ distribution obtained from the high particle concentration data alone. The lower particle concentration freezing curves were accurately predicted by randomly sampling active site abilities $(\theta)$ from $\bar{g}$ and averaging their resultant freezing probabilities. This framework provides a new method for extrapolating droplet freezing temperature spectra from cold plate experimental data under high particle concentrations to atmospherically realistic dilute particle-droplet systems.

We found that the shifts to colder freezing temperatures caused by reducing the particle concentration or total surface area present in droplets cannot be fully accounted for by simply normalizing to the available surface area, as is done in the ice active site density $\left(n_{\mathrm{S}}\right)$ analysis framework. When the surface area is below the critical area threshold, the retrieved values of $n_{\mathrm{s}}$ can increase significantly for the same particle species when the particle concentration is decreased. Above the critical area threshold, the same $n_{\mathrm{s}}$ curves are retrieved when particle concentration is changed. Atmospheric cloud droplets typically contain just one particle each. Therefore, this effect of particle concentration on droplet freezing temperature spectra and the retrieved $n_{\mathrm{S}}$ values has important implications for the extrapolation of cold plate droplet freezing measurements to describe the ice nucleation properties of realistic atmospheric particles.

Systems that probe populations of droplets each containing one particle, such as the CFDC, are unable to probe a large particle-in-droplet concentration range but are powerful tools for the real-time investigations of INPs at the realistic individual particle level (DeMott et al., 2010; Sullivan 
et al., 2010a; Welti et al., 2009). The frozen fraction curves produced from such an instrument do not provide enough information to associate the observed variability in ice nucleation ability to internal or external factors. However, future laboratory studies using the critical area cold plate technique we have introduced here (e.g., Fig. 4) will provide new insight into the critical area thresholds of internal variability in ice active site ability for different species. This will produce more informed assumptions regarding the variability in ice nucleation properties observed through online field instruments, specifically when the measurements are made in conjunction with single-particle chemical analysis techniques (Creamean et al., 2013; DeMott et al., 2003, 2010; Prather et al., 2013; Worringen et al., 2015).

Atmospherically relevant particle sizes may very well fall below the critical area threshold for an individual particle, at least for some species such as illite mineral particles considered here. Therefore, average ice nucleation spectra or active site distributions such as $n_{\mathrm{S}}$ and $\bar{g}$ may not be applicable for representing the ice nucleation properties of particles in cloud and atmospheric models. However, careful examination of the surface area dependence of ice nucleating ability of a species allows more accurate retrievals of active site density distributions that properly encompass this dependence.

\section{Data availability}

The data is available upon request to R. Sullivan (rsullivan@cmu.edu).

Acknowledgements. This research was partially supported by the National Science Foundation (award CHE-1213718), and M. Polen was supported by a NSF Graduate Research Fellowship. The authors thank Paul DeMott for valuable discussions regarding an earlier version of this framework. Naruki Hiranuma at AIDA is acknowledged for providing us with the MCC cellulose and illite NX samples, as part of the INUIT project.

Edited by: H. Grothe

Reviewed by: G. Vali and one anonymous referee

\section{References}

Alpert, P. A. and Knopf, D. A.: Analysis of isothermal and coolingrate-dependent immersion freezing by a unifying stochastic ice nucleation model, Atmos. Chem. Phys., 16, 2083-2107, doi:10.5194/acp-16-2083-2016, 2016.

Baker, M. B. and Peter, T.: Small-scale cloud processes and climate, Nature, 451, 299-300, doi:10.1038/nature06594, 2008.

Barahona, D.: On the ice nucleation spectrum, Atmos. Chem. Phys., 12, 3733-3752, doi:10.5194/acp-12-3733-2012, 2012.

Broadley, S. L., Murray, B. J., Herbert, R. J., Atkinson, J. D., Dobbie, S., Malkin, T. L., Condliffe, E., and Neve, L.: Immersion mode heterogeneous ice nucleation by an illite rich powder representative of atmospheric mineral dust, Atmos. Chem. Phys., 12, 287-307, doi:10.5194/acp-12-287-2012, 2012.

Cantrell, W. and Heymsfield, A.: Production of Ice in Tropospheric Clouds: A Review, B. Am. Meteorol. Soc., 86, 795-807, doi:10.1175/BAMS-86-6-795, 2005.

Creamean, J. M., Suski, K. J., Rosenfeld, D., Cazorla, A., DeMott, P. J., Sullivan, R. C., White, A. B., Ralph, F. M., Minnis, P., Comstock, J. M., Tomlinson, J. M., and Prather, K. A.: Dust and biological aerosols from the Sahara and Asia influence precipitation in the western U.S., Science, 339, 1572-1578, doi:10.1126/science.1227279, 2013.

DeMott, P. J., Cziczo, D. J., Prenni, A. J., Murphy, D. M., Kreidenweis, S. M., Thomson, D. S., Borys, R., and Rogers, D. C.: Measurements of the concentration and composition of nuclei for cirrus formation, P. Natl. Acad. Sci. USA, 100, 14655-60, doi:10.1073/pnas.2532677100, 2003.

DeMott, P. J., Prenni, A. J., Liu, X., Kreidenweis, S. M., Petters, M. D., Twohy, C. H., and Richardson, M. S.: Predicting global atmospheric ice nuclei distributions and their impacts on climate, P. Natl. Acad. Sci. USA, 107, 11217-11222, doi:10.1073/pnas.0910818107, 2010.

Eidhammer, T., DeMott, P. J., and Kreidenweis, S. M.: A comparison of heterogeneous ice nucleation parameterizations using a parcel model framework, J. Geophys. Res., 114, D06202, doi:10.1029/2008jd011095, 2009.

Emersic, C., Connolly, P. J., Boult, S., Campana, M., and Li, Z.: Investigating the discrepancy between wet-suspension- and drydispersion-derived ice nucleation efficiency of mineral particles, Atmos. Chem. Phys., 15, 11311-11326, doi:10.5194/acp15-11311-2015, 2015.

Ervens, B. and Feingold, G.: On the representation of immersion and condensation freezing in cloud models using different nucleation schemes, Atmos. Chem. Phys., 12, 5807-5826, doi:10.5194/acp-12-5807-2012, 2012.

Ervens, B. and Feingold, G.: Sensitivities of immersion freezing: Reconciling classical nucleation theory and deterministic expressions, Geophys. Res. Lett., 40, 3320-3324, doi:10.1002/grl.50580, 2013.

Ervens, B., Feingold, G., Sulia, K., and Harrington, J.: The impact of microphysical parameters, ice nucleation mode, and habit growth on the ice/liquid partitioning in mixed-phase Arctic clouds, J. Geophys. Res., 116, D17205, doi:10.1029/2011JD015729, 2011.

Fletcher, N. H.: Active Sites and Ice Crystal Nucleation, J. Atmos. Sci., 26, 1266-1271, doi:10.1175/15200469(1969)026<1266:ASAICN>2.0.CO;2, 1969.

Fornea, A. P., Brooks, S. D., Dooley, J. B., and Saha, A.: Heterogeneous freezing of ice on atmospheric aerosols containing ash, soot, and soil, J. Geophys. Res., 114, D13201, doi:10.1029/2009JD011958, 2009.

Hartmann, S., Wex, H., Clauss, T., Augustin-Bauditz, S., Niedermeier, D., Rösch, M., and Stratmann, F.: Immersion Freezing of Kaolinite: Scaling with Particle Surface Area, J. Atmos. Sci., 73, 263-278, doi:10.1175/JAS-D-15-0057.1, 2016.

Herbert, R. J., Murray, B. J., Whale, T. F., Dobbie, S. J., and Atkinson, J. D.: Representing time-dependent freezing behaviour in immersion mode ice nucleation, Atmos. Chem. Phys., 14, 85018520, doi:10.5194/acp-14-8501-2014, 2014. 
Hiranuma, N., Augustin-Bauditz, S., Bingemer, H., Budke, C., Curtius, J., Danielczok, A., Diehl, K., Dreischmeier, K., Ebert, M., Frank, F., Hoffmann, N., Kandler, K., Kiselev, A., Koop, T., Leisner, T., Möhler, O., Nillius, B., Peckhaus, A., Rose, D., Weinbruch, S., Wex, H., Boose, Y., DeMott, P. J., Hader, J. D., Hill, T. C. J., Kanji, Z. A., Kulkarni, G., Levin, E. J. T., McCluskey, C. S., Murakami, M., Murray, B. J., Niedermeier, D., Petters, M. D., O’Sullivan, D., Saito, A., Schill, G. P., Tajiri, T., Tolbert, M. A., Welti, A., Whale, T. F., Wright, T. P., and Yamashita, K.: A comprehensive laboratory study on the immersion freezing behavior of illite NX particles: a comparison of 17 ice nucleation measurement techniques, Atmos. Chem. Phys., 15, 2489-2518, doi:10.5194/acp-15-2489-2015, 2015a.

Hiranuma, N., Möhler, O., Yamashita, K., Tajiri, T., Saito, A., Kiselev, A., Hoffmann, N., Hoose, C., Jantsch, E., Koop, T., and Murakami, M.: Ice nucleation by cellulose and its potential contribution to ice formation in clouds, Nat. Geosci., 8, 273-277, doi:10.1038/ngeo2374, 2015b.

Hoose, C. and Möhler, O.: Heterogeneous ice nucleation on atmospheric aerosols: a review of results from laboratory experiments, Atmos. Chem. Phys., 12, 9817-9854, doi:10.5194/acp-12-98172012, 2012.

Hoose, C., Lohmann, U., Erdin, R., and Tegen, I.: The global influence of dust mineralogical composition on heterogeneous ice nucleation in mixed-phase clouds, Environ. Res. Lett., 3, 25003, doi:10.1088/1748-9326/3/2/025003, 2008.

Hoose, C., Kristjánsson, J. E., Chen, J.-P., and Hazra, A.: A Classical-Theory-Based Parameterization of Heterogeneous Ice Nucleation by Mineral Dust, Soot, and Biological Particles in a Global Climate Model, J. Atmos. Sci., 67, 2483-2503, 2010.

Koehler, K. A., Kreidenweis, S. M., DeMott, P. J., Petters, M. D., Prenni, A. J., and Möhler, O.: Laboratory investigations of the impact of mineral dust aerosol on cold cloud formation, Atmos. Chem. Phys., 10, 11955-11968, doi:10.5194/acp10-11955-2010, 2010.

Koop, T., Luo, B., Tsias, A., and Peter, T.: Water activity as the determinant for homogeneous ice nucleation in aqueous solutions, Nature, 406, 611-614, doi:10.1038/35020537, 2000.

Levine, J.: Statistical explanation of spontaneous freezing of water droplets, NACA Tech, 2234, Cleveland, OH, USA, 1950.

Liu, X. and Penner, J. E.: Ice nucleation parameterization for global models, Meteorol. Z., 14, 499-514, 2005.

Lüönd, F., Stetzer, O., Welti, A., and Lohmann, U.: Experimental study on the ice nucleation ability of size-selected kaolinite particles in the immersion mode, J. Geophys. Res., 115, D14201, doi:10.1029/2009JD012959, 2010.

Marcolli, C., Gedamke, S., Peter, T., and Zobrist, B.: Efficiency of immersion mode ice nucleation on surrogates of mineral dust, Atmos. Chem. Phys., 7, 5081-5091, doi:10.5194/acp-7-50812007, 2007.

Meyers, M. P., DeMott, P. J., and Cotton, W. R.: New Primary Ice-Nucleation Parameterizations in an Explicit Cloud Model, J. Appl. Meteorol., 31, 708-721, doi:10.1175/15200450(1992)031<0708:NPINPI>2.0.CO;2, 1992.

Mülmenstädt, J., Sourdeval, O., Delanoë, J., and Quaas, J.: Frequency of occurrence of rain from liquid-, mixed-, and ice-phase clouds derived from A-Train satellite retrievals, Geophys. Res. Lett., 42, 6502-6509, doi:10.1002/2015GL064604, 2015.
Murray, B. J., Broadley, S. L., Wilson, T. W., Atkinson, J. D., and Wills, R. H.: Heterogeneous freezing of water droplets containing kaolinite particles, Atmos. Chem. Phys., 11, 4191-4207, doi:10.5194/acp-11-4191-2011, 2011.

Murray, B. J., O'Sullivan, D., Atkinson, J. D., and Webb, M. E.: Ice nucleation by particles immersed in supercooled cloud droplets, Chem. Soc. Rev., 41, 6519, doi:10.1039/c2cs35200a, 2012.

Niedermeier, D., Shaw, R. A., Hartmann, S., Wex, H., Clauss, T., Voigtländer, J., and Stratmann, F.: Heterogeneous ice nucleation: exploring the transition from stochastic to singular freezing behavior, Atmos. Chem. Phys., 11, 8767-8775, doi:10.5194/acp11-8767-2011, 2011.

Pandey, R., Usui, K., Livingstone, R. A., Fischer, S. A., Pfaendtner, J., Backus, E. H. G., Nagata, Y., Fröhlich-nowoisky, J., Schmüser, L., Mauri, S., Scheel, J. F., Knopf, D. A., Pöschl, U., Bonn, M., and Weidner, T.: Ice-nucleating bacteria control the order and dynamics of interfacial water, Sci. Adv., 2, 1-9, doi:10.1126/sciadv.1501630, 2016.

Phillips, V. T. J., DeMott, P. J., and Andronache, C.: An Empirical Parameterization of Heterogeneous Ice Nucleation for Multiple Chemical Species of Aerosol, J. Atmos. Sci., 65, 2757-2783, doi:10.1175/2007JAS2546.1, 2008.

Phillips, V. T. J., Demott, P. J., Andronache, C., Pratt, K. A., Prather, K. A., Subramanian, R., and Twohy, C.: Improvements to an Empirical Parameterization of Heterogeneous Ice Nucleation and Its Comparison with Observations, J. Atmos. Sci., 70, 378-409, doi:10.1175/JAS-D-12-080.1, 2013.

Polen, M., Lawlis, E., and Sullivan, R. C.: The unstable ice nucleation properties of Snomax ${ }^{\circledR}$ bacterial particles, J. Geophys. Res.-Atmos., doi:10.1002/2016JD025251, in press, 2016.

Prather, K. A., Bertram, T. H., Grassian, V. H., Deane, G. B., Stokes, M. D., Demott, P. J., Aluwihare, L. I., Palenik, B. P., Azam, F., Seinfeld, J. H., Moffet, R. C., Molina, M. J., Cappa, C. D., Geiger, F. M., Roberts, G. C., Russell, L. M., Ault, A. P., Baltrusaitis, J., Collins, D. B., Corrigan, C. E., Cuadra-Rodriguez, L. a, Ebben, C. J., Forestieri, S. D., Guasco, T. L., Hersey, S. P., Kim, M. J., Lambert, W. F., Modini, R. L., Mui, W., Pedler, B. E., Ruppel, M. J., Ryder, O. S., Schoepp, N. G., Sullivan, R. C., and Zhao, D.: Bringing the ocean into the laboratory to probe the chemical complexity of sea spray aerosol, P. Natl. Acad. Sci USA, 110, 7550-7555, doi:10.1073/pnas.1300262110, 2013.

Pruppacher, H. R. and Klett, J. D.: Microphysics of Clouds and Precipitation, edited by: Rosen, R. D., Kluwer Academic Publishers, 1997.

Rosenfeld, D., Lohmann, U., Raga, G. B., O’Dowd, C. D., Kulmala, M., Fuzzi, S., Reissell, A., and Andreae, M. O.: Flood or Drought: How Do Aerosols Affect Precipitation?, Science, 321, 1309-1313, doi:10.1126/science.1160606, 2008.

Sear, R. P.: Generalisation of Levine's prediction for the distribution of freezing temperatures of droplets: a general singular model for ice nucleation, Atmos. Chem. Phys., 13, 7215-7223, doi:10.5194/acp-13-7215-2013, 2013.

Sullivan, R. C., Miñambres, L., DeMott, P. J., Prenni, A. J., Carrico, C. M., Levin, E. J. T., and Kreidenweis, S. M.: Chemical processing does not always impair heterogeneous ice nucleation of mineral dust particles, Geophys. Res. Lett., 37, L24805, doi:10.1029/2010GL045540, 2010a.

Sullivan, R. C., Petters, M. D., DeMott, P. J., Kreidenweis, S. M., Wex, H., Niedermeier, D., Hartmann, S., Clauss, T., Stratmann, 
F., Reitz, P., Schneider, J., and Sierau, B.: Irreversible loss of ice nucleation active sites in mineral dust particles caused by sulphuric acid condensation, Atmos. Chem. Phys., 10, 1147111487, doi:10.5194/acp-10-11471-2010, 2010 b.

Turner, M. A., Arellano, F., and Kozloff, L. M.: Three separate classes of bacterial ice nucleation structures, J. Bacteriol., 172, 2521-2526, 1990.

Vali, G.: Quantitative Evaluation of Experimental Results an the Heterogeneous Freezing Nucleation of Supercooled Liquids, J. Atmos. Sci., 28, 402-409, doi:10.1175/15200469(1971)028<0402:QEOERA>2.0.CO;2, 1971.

Vali, G.: Freezing Rate Due to Heterogeneous Nucleation, J. Atmos. Sci., 51, 1843-1856, doi:10.1175/15200469(1994)051<1843:FRDTHN>2.0.CO;2, 1994.

Vali, G.: Repeatability and randomness in heterogeneous freezing nucleation, Atmos. Chem. Phys., 8, 5017-5031, doi:10.5194/acp-8-5017-2008, 2008.

Vali, G.: Interpretation of freezing nucleation experiments: singular and stochastic; sites and surfaces, Atmos. Chem. Phys., 14, 5271-5294, doi:10.5194/acp-14-5271-2014, 2014.

Vali, G. and Snider, J. R.: Time-dependent freezing rate parcel model, Atmos. Chem. Phys., 15, 2071-2079, doi:10.5194/acp15-2071-2015, 2015.

Vali, G. and Stransbury, E. J.: Time Dependant Characteristics of the Heterogeneous Nucleation of Ice, Can. J. Phys., 44, 477-502, 1966.

Vali, G., DeMott, P. J., Möhler, O., and Whale, T. F.: Technical Note: A proposal for ice nucleation terminology, Atmos. Chem. Phys., 15, 10263-10270, doi:10.5194/acp-15-10263-2015, 2015.

Welti, A., Lüönd, F., Stetzer, O., and Lohmann, U.: Influence of particle size on the ice nucleating ability of mineral dusts, Atmos. Chem. Phys., 9, 6705-6715, doi:10.5194/acp-9-6705-2009, 2009.

Welti, A., Lüönd, F., Kanji, Z. A., Stetzer, O., and Lohmann, U.: Time dependence of immersion freezing: an experimental study on size selected kaolinite particles, Atmos. Chem. Phys., 12, 9893-9907, doi:10.5194/acp-12-9893-2012, 2012.
Wex, H., Augustin-Bauditz, S., Boose, Y., Budke, C., Curtius, J., Diehl, K., Dreyer, A., Frank, F., Hartmann, S., Hiranuma, N., Jantsch, E., Kanji, Z. A., Kiselev, A., Koop, T., Möhler, O., Niedermeier, D., Nillius, B., Rösch, M., Rose, D., Schmidt, C., Steinke, I., and Stratmann, F.: Intercomparing different devices for the investigation of ice nucleating particles using Snomax ${ }^{\circledR}$ as test substance, Atmos. Chem. Phys., 15, $1463-$ 1485, doi:10.5194/acp-15-1463-2015, 2015.

Wheeler, M. J. and Bertram, A. K.: Deposition nucleation on mineral dust particles: a case against classical nucleation theory with the assumption of a single contact angle, Atmos. Chem. Phys., 12, 1189-1201, doi:10.5194/acp-12-1189-2012, 2012.

Worringen, A., Kandler, K., Benker, N., Dirsch, T., Mertes, S., Schenk, L., Kästner, U., Frank, F., Nillius, B., Bundke, U., Rose, D., Curtius, J., Kupiszewski, P., Weingartner, E., Vochezer, P., Schneider, J., Schmidt, S., Weinbruch, S., and Ebert, M.: Singleparticle characterization of ice-nucleating particles and ice particle residuals sampled by three different techniques, Atmos. Chem. Phys., 15, 4161-4178, doi:10.5194/acp-15-4161-2015, 2015.

Wright, T. P. and Petters, M. D.: The role of time in heterogeneous freezing nucleation, J. Geophys. Res.-Atmos., 118, 3731-3743, 2013.

Wright, T. P., Petters, M. D., Hader, J. D., Morton, T., and Holder, A. L.: Minimal cooling rate dependence of ice nuclei activity in the immersion mode, J. Geophys. Res.-Atmos., 118, 10535-10543, doi:10.1002/jgrd.50810, 2013.

Yankofsky, S. A., Levin, Z., Bertold, T., and Sandlerman, N.: Some Basic Characteristics of Bacterial Freezing Nuclei, J. Appl. Meteorol., 20, 1013-1019, doi:10.1175/15200450(1981)020<1013:SBCOBF>2.0.CO;2, 1981.

Zobrist, B., Koop, T., Luo, B. P., Marcolli, C., and Peter, T.: Heterogeneous ice nucleation rate coefficient of water droplets coated by a nonadecanol monolayer, J. Phys. Chem. C, 111, 2149-2155, doi:10.1021/jp066080w, 2007. 